\title{
A synthesis of the POMME physical data set: One year monitoring of the upper layer
}

\author{
F. Gaillard*, H. Mercier, and C. Kermabon
}

Laboratoire de physique des océans, IFREMER, BP 70, 29280 Plouzané, France.

*: Corresponding author : (Fabienne.Gaillard@ifremer.fr)

\begin{abstract}
:
The Programme Océan Multidisciplinaire Méso Echelle (POMME) experiment was designed to describe and quantify the role of mesoscale processes in the subduction of mode waters in the northeast Atlantic. During 1 year (September 2000-October 2001), in situ measurements were conducted over a $8^{\circ}$ square area centered on $18^{\circ} \mathrm{W}, 42^{\circ} \mathrm{N}$. We present the synthesis of the physical data set collected during this experiment. To improve time and space coverages, these measurements are combined with satellite information from sea surface temperature and altimetry. Daily fields of temperature, salinity, and stream function are produced over a seasonal cycle with a simplified Kalman filter. We analyze the annual cycle of the upper layer. The 1 year mean circulation in the upper $400 \mathrm{~m}$ resembles the scheme proposed by Paillet and Mercier (1997). The meridional component of the flow carries cold water southward, thus contributing to cool the POMME area. The annual mean heat budget shows that this advection by the mean current nearly balances the warming by the surface heat fluxes. The mixed layer maximum depth is reached in March. It increases, in zonal averages, from $100 \mathrm{~m}$ south of $38^{\circ} \mathrm{N}$ to more than $270 \mathrm{~m}$ north of $45^{\circ} \mathrm{N}$ and, remarkably, is shaped by the mesoscale. The subpolar mode water formed in the north of the POMME area has a lower density (26.8-27.0) than the mode water formed in the years 1988-1990 that Paillet and Arhan (1996) found in the density range (27.0-27.1). This mode water is continuously advected southward across the $42^{\circ} \mathrm{N}$ latitude, leading to an annual mean transport of $1.410^{6} \mathrm{~m}^{3} \mathrm{~s}^{-1}$.
\end{abstract}




\section{Introduction}

The northeast Atlantic subpolar mode water is formed during the winter North of the marked discontinuity in the mixed layer depth located at about $40^{\circ} \mathrm{N}$ [Marshall et al., 1993]. Part of this mode water is advected southward and escapes the formation area to subduct into the main thermocline. According to Paillet and Mercier [1997] advection is performed by a weak mean current, found as the solution of a geostrophic inverse model. However, recent observations did not reveal this southward flow and suggested that eddies might be important for the subduction of the northeast Atlantic subpolar mode water [Cunningham, 2000], [Leach et al., 2002]. The POMME experiment took place off the Iberian Peninsula from September 2000 to October 2001. It was designed to investigate the role of eddies in the physical, biological and bio-chemistry property transfers from the surface to the deeper layers. The experiment, described by Memery et al. [2005], combined local, intensive observation sites with a global monitoring of the eddy activity and the large scale environment.

Two types of gridded fields were produced in real time from the POMME data set. An operational prototype was operated to analyze the temperature field, mainly from profilers, CTD and XBT data. The currents were also computed in near real time by Assenbaum and Reverdin [2005]. They combined the POMME in situ data set available at that time with SOPRANE operational analysis based on altimetry, putting the emphasis on mesoscale mapping and the structure identification. They analyzed the streamfunction on 4 levels $(0,400,1000$ and $1800 \mathrm{~m})$ propagating information upward, starting from the deepest level, through the vertical shear provided by density profiles. Their results confirmed both the overall good quality of the SOPRANE 
analysis and the importance of float trajectories for improving the position and strength of the mesoscale structures.

The phase of intense deepening and retreat of the mixed layer was modeled by Giordani et al. [2005] with a 3D mixed layer model forced with the surface fluxes computed by Caniaux et al. [2005a]. They simulated the evolution of the upper layer from POMME-1 (February) to POMME-2 (April). The mass field was initialized from an analysis based on POMME-1 CTD data and the geostrophic component of the velocity was constructed by an interpolation of geostrophic currents between POMME-1 and POMME-2, complemented by the SOPRANE analysis.

We present a synthesis of the physical data sets based on a Kalman filter in the form of daily 3D gridded fields of temperature, salinity and current during the observed annual cycle. This analysis is in the continuity of the real-time studies initiated during the POMME experiment and relies on their results. The data set is presented in section 2. The fields are constructed in a reduced space obtained by projecting the variables on vertical modes based on the statistical analysis of a CTD database and on horizontal Fourier components (section 3). The simplified Kalman filter is exposed in section 4. The estimated fields are validated by checking their consistency with a priori knowledge and data (section 5). Section 6 focuses on the upper layer variability and mode water formation. We analyze the main features of the circulation and study the annual heat balance, we document the time and space variability of the mixed layer depth and its relation with surface forcing and mesoscale variability. Finally we characterize the mode water formed during the 2000-2001 winter and quantify its southward export.

\section{Data}


Four cruises (P0, P1, P2, P3), each involving two vessels, were carried out during the 13 months duration (September 2000 to October 2001) of POMME in the area centered on $18^{\circ} \mathrm{W}$ $-42^{\circ} \mathrm{N}$ (Figure 1, Table 1). Temperature and salinity profiles and current measurements were performed during the cruises. In between, observations were collected with moored and drifting instruments. A summary of the POMME data set is given in Table 1.

The vertical profiles of temperature and salinity come from the CTDs and the ARGO profilers that cover the range $0-2000 \mathrm{~m}$. Additional profiles are provided by XCTDs, XBTs and the drifting 'Marisonde' surface buoys equipped with $200 \mathrm{~m}$ long thermistor chains. The distribution of temperature profiles over time and depth shows a strong increase in the number of profiles in February 2001, at the beginning of the intensive observation period, mainly in the depth range sampled by the surface buoys (Figure 2). Salinity profiles are available almost exclusively during the cruises.

Current profiles from Vessel Mounted Acoustic Doppler Current Profilers (VMADCP) were collected during each POMME cruise and one opportunity cruise in late July 2001. These data were averaged along track in $10 \mathrm{~km}$ bins. The maximum depth range of current profiles varies with the quality of the acoustic data, but $50 \%$ of the data reach at least $600 \mathrm{~m}$ (Figure 2).

Times series include both Eulerian and Lagrangian data. Nine mooring were deployed to collect current and temperature and a few salinity series with time sampling of 1 hour or less. The mooring positions and depth samplings are given on Figure 3. The time series were filtered using a second order Butterworth filter with 48-hour cut-off frequency and under-sampled at 1 day by bin averaging. Three types of deep, acoustically tracked, lagrangian floats were used: RAFOS, VCM and MARVOR [Le Cann et al., 2005]. They provide temperatures and velocities 
(deduced from the daily displacements). Most floats were deployed in the 200-500m layer, but some data exist at 1000 and $1500 \mathrm{~m}$ (Figure 3).

In addition to the in situ measurements, we use two gridded fields produced by independent analysis. The first is the horizontal current fields produced by the French Navy SOPRANE operational system. The fields result from a re-analysis based on a sequential assimilation of altimetry in a quasi-geostrophic model. This dynamical analysis was preferred to raw altimeter data because it solves the geoid problem. To remain as close as possible to the original data, we use only the shallowest SOPRANE level $(100 \mathrm{~m})$. Streamfunction values with $0.1^{\circ}$ horizontal resolution were produced once a week over the domain $\left[33^{\circ} \mathrm{N}-48.7^{\circ} \mathrm{N}, 25^{\circ} \mathrm{W}-8.3^{\circ} \mathrm{W}\right]$. Since we do not expect to resolve such scales over the duration of the experiment, and to reduce the size of the data vector, we compute the currents on the full SOPRANE grid, and sub-sample them at $0.4^{\circ}$. The errors on SOPRANE currents are deduced from the Sea Level Anomaly errors provided with the altimetry data.

The second gridded product is the Sea Surface Temperature (SST) analysis performed at CNRM by Caniaux et al. [2005a]. The SST fields were computed every 3 days over the domain $\left[35^{\circ} \mathrm{N}-47.8^{\circ} \mathrm{N}, 23.33^{\circ} \mathrm{W}-13.53^{\circ} \mathrm{W}\right]$ with $5 \mathrm{~km}$ resolution, and interpolated to obtain daily fields for fluxes calculations. We extracted one point over 4 in each space direction and use 2 fields per week (on days 2 and 5).

The main difference between the data set used by Assenbaum and Reverdin [2005] and this analysis is that we use additional data sets such as the VMADCP data, MADCP data from the South mooring and the SST fields that were not relevant to their analysis. On the other hand, we do not use surface buoy trajectories to avoid dealing with wind drift nor we use profiler displacements because of aliasing errors introduced by the 10 days trajectory sampling. 


\section{Representation of the physical fields}

The physical data collected during POMME are used to estimate fields of temperature, salinity and streamfunction over the duration of the experiment. The method, based on a Kalman filter, was previously applied to study deep winter convection in the Mediterranean with streamfunction as the only estimated variable [Gaillard et al., 2000]. For POMME, the formalism is extended to explicitly estimate temperature and salinity in addition to streamfunction.

Because the 3D temperature, salinity and streamfunction fields over the POMME area and their evolutions during the year of the experiment represent a considerable number of variables, a first step is to decrease the size of the system. An order reduction is efficiently performed by projecting the physical fields on the first leading eigenvectors of their covariance matrix. Those vectors are usually referred to as empirical orthogonal functions (EOFs). Along those lines, Kaplan et al. [1997] used two-dimensional horizontal EOFs to analyze the sea-surface temperature variations over the Atlantic. In our case different behaviors are expected in the vertical and the horizontal. The vertical structure is strongly linked to the stratification and is efficiently represented by EOFs. In the horizontal, the variability is dominated by mesoscale and homogeneously distributed. Thus, following Gaillard et al. [2000], we use EOFs in the vertical and the horizontal variability is represented by Fourier components.

\subsection{Vertical functions}

Different strategies can be used to define the vertical EOFs. The simplest is to compute temperature and salinity modes independently. This representation is accurate, but requires a large number of modes since no information on $\theta-\mathrm{S}$ relation is involved. An alternative is proposed by Fukumori et al. [1991] who computed coupled modes for temperature and salinity anomalies. In that case, the number of modes required to reconstruct both types of anomalies is 
usually smaller than with independent modes. The drawback is that the $\theta$-S relation is built in the modes. In the POMME area, which experiments strong surface cooling/heating and where the Mediterranean water produces high water mass contrasts, this representation may impose too strong a coupling between $\theta$ and S. We searched a compromise between those two methods by taking into account some information on the $\theta$ and $\mathrm{S}$ coupling externally. The change of reference coordinates, from depth to density, as proposed by Faucher et al. [2002], was not considered since such transformation fails in the mixed layer, which is the prime objective of this study.

\subsubsection{Temperature and salinity mode definitions}

Temperature $(T)$ and salinity $(S)$ are decomposed into a mean known component $\left(T_{0}, S_{0}\right)$, called the reference state, and an unknown time varying anomaly $\left(T^{\prime}, S^{\prime}\right)$. The temperature anomaly is projected on a finite number of vertical empirical orthogonal functions (EOFs):

$$
T^{\prime}=\sum_{k=1}^{N_{T}} \mu_{k}^{T}(x, y) L_{k}^{T}(z)
$$

To each temperature mode, we associate a neutral salinity mode, computed such that a temperature anomaly produces no density anomaly. The conversion from temperature to neutral salinity is obtained by setting $\rho^{\prime}=0$ in the linearized state equation that involves the thermal and haline expansion coefficients:

$$
\rho^{\prime}=\frac{\partial \rho}{\partial T} T^{\prime}+\frac{\partial \rho}{\partial S} S^{\prime}
$$

We obtain:

$$
L_{k}^{S n}=\alpha(z) L_{k}^{T}, \text { with } \alpha(z)=-\frac{(\partial \rho / \partial T)}{(\partial \rho / \partial S)} .
$$

The salinity profiles of the database are projected on these neutral salinity modes. A second set of salinity EOFs, $\left(L_{k}^{s a}\right)$, called active modes, is extracted from the projection residuals. A 
salinity profile is finally expressed as the sum of a neutral $\left(S_{n}\right)$ and an active $\left(S_{a}\right)$ components:

$$
S^{\prime}=\sum_{k=1}^{N_{T}} \mu_{k}^{T}(x, y) \alpha(z) L_{k}^{T}(z)+\sum_{k=1}^{N_{s a}} \mu_{k}^{s a}(x, y) L_{k}^{s a}(z) .
$$

Note that no assumption on $\theta$-S relationship has been made at this stage (see section 3.1.4).

\subsubsection{Streamfunction mode definition}

In quasi-geostrophic theory, the baroclinic component of the streamfunction is related to the density anomaly:

$$
\rho^{\prime}=-\frac{f_{0} \rho_{0}}{g} \frac{\partial \Psi}{\partial z}
$$

which, by definition, is deduced from the active salinity component:

$$
\rho^{\prime}=\beta(z) S_{a}, \text { with } \beta(z)=\frac{\partial \rho}{\partial S}
$$

Thus the density anomaly writes:

$$
\rho^{\prime}=\sum_{k=1}^{N_{s a}} \mu_{k}^{s a}(x, y) \beta(z) L_{k}^{s a}(z)
$$

The baroclinic streamfunction modes $L_{k}^{\psi}(z)$ are obtained by vertically integrating the density modes (equation 5), the integration level $z_{0}$ is defined by imposing that the vertical integral of the mode be zero:

$$
L_{k}^{\psi}(z)=-\frac{g}{f_{0} \rho_{0}} \int_{z_{0}}^{z} \beta\left(z^{\prime}\right) L_{k}^{s a}\left(z^{\prime}\right) d z^{\prime}, \quad \int_{-H}^{0} L_{k}^{\psi}(z) d z=0
$$

A barotropic mode is added to the baroclinic streamfunction bases and the streamfunction is expressed as:

$$
\Psi=\mu_{0}(x, y)+\sum_{k=1}^{N_{s a}} \mu_{k}^{s a}(x, y) L_{k}^{\Psi}(z)
$$

The horizontal components of the geostrophic velocity $\vec{u}$ are derived from the streamfunction:

$$
u=-\frac{\partial \Psi}{\partial y}, \quad v=+\frac{\partial \Psi}{\partial x}
$$




\subsubsection{EOF computations}

The reference states for temperature and salinity $\left(T_{0}(z), S_{0}(z)\right)$, and the vertical modes are computed from a CTD database covering the period 1988-2001. The database includes profiles from LPO cruises Bord-Est, ARCANE and CAMBIOS, data from WHOI 'Hydrobase' and the POMME deep CTD profiles. The selection area is slightly enlarged with respect to the strict POMME area, allowing for a better sampling of the water mass variability. The 758 selected profiles reach at least $2200 \mathrm{~m}$, the maximum depth of the layer that is reconstructed by the analysis. The CTD profiles are sub-sampled on 250 levels, with vertical spacing increasing from $5 \mathrm{~m}$ in layer $0-400 \mathrm{~m}$ to $10 \mathrm{~m}$ in layer $400 \mathrm{~m}-2000 \mathrm{~m}$ and $20 \mathrm{~m}$ below. The distribution over space and time is given on Figure 4. Data for the 2000-2001 period are all from the POMME data set. The seasonal cycle is not evenly sampled, with late fall and early winter poorly represented, but the extreme months (coldest: March, warmest: August) are present in the database.

The functions $\alpha(z)$ and $\beta(z)$ are determined from the same database. At each level we compute the density anomalies produced by salinity and temperature perturbations and the values of the expansion coefficients are obtained by a linear fit over all anomalies. The EOFs are constructed in the sequence described in the previous section. The singular value decomposition (SVD) of the profile anomaly matrix gives the modes (first set of eigenvectors), the coefficients (second set of eigenvectors) and the variances of the modes (the singular values). A stronger weight was imposed on the surface layers to perform the SVD. The reference profiles and the 3 leading modes of each set are shown on Figure 5. Temperature modes have two maxima, one at the surface, and the second near the Mediterranean water level. The first active salinity mode is strongly surface intensified, it represents the large seasonal density change. 
The number of modes used to represent the variables results from a trade-off between the accuracy of the reconstructed profiles and the number of degrees of freedom that the system is able to estimate. A representation based on 8 temperature modes and 6 active salinity modes keeps the RMS errors at an acceptable level for temperature, salinity and density (see Table 2) while reducing significantly the order of the system. We capture $82 \%$ of the temperature variance with the first set of 8 modes and $85 \%$ of the remaining salinity variance with the 6 active salinity modes.

\subsubsection{Additional $\theta-S$ constraint}

A quick look at the full data set reveals the sparsity of salinity measurements at all levels. When only temperature is observed, the estimation system proposes a salinity based on zero density anomaly, unless previous or neighboring data provide the missing salinity information. This implicit a priori information is acceptable at depth, but may lead to grossly erroneous salinity near surface: seasonal warming and cooling does not occur at constant density. To compensate for this tendency, we introduce a statistical $\theta-\mathrm{S}$ relation computed as follows. At each level, a third degree polynomial is fitted in the $\theta$-S plane, through the 2D-histogram of the data, each point being weighted by the histogram frequency. We obtain a depth dependent relation, $S=\alpha_{o b s}(T)$, and the associated fit error. Figure 6 illustrates this relation overlayed on the $\theta$-S diagram for the POMME CTDs at 4 levels $(50,300,800$ and $1000 \mathrm{~m})$. Then, for each temperature profile lacking salinity measurement, a pseudo-salinity profile is computed using the $\theta-\mathrm{S}$ relation, and the fit error is used as data error.

A somewhat similar technique was applied by Ricci et al. [2005] in a data assimilation experiment in the equatorial Pacific. These authors introduced a linearized $\theta$-S constraint $S^{\prime}=\alpha_{v} T^{\prime}$. They assumed temperature and salinity variations to occur predominantly through vertical dis- 
placements and $\alpha_{v}$ is deduced from the vertical gradients of the reference profiles $\left(\alpha_{v}=\frac{\partial S / \partial z}{\partial T / \partial z}\right)$. This assumption, which holds in the equatorial thermocline, fails in the North-East Atlantic, where different water masses are encountered at the same level. Figure 6 compares $\alpha_{v}$ with $\alpha_{o b s}$ at different levels. Ricci et al. [2005] method is valid only within the North Atlantic Central Water $(300 \mathrm{~m})$, where $\alpha_{v}$ is similar to the statistical $\theta$-S relation. It gives poor results at the Mediterranean water levels (800 and $1000 \mathrm{~m}$ ).

\subsection{Horizontal representation}

The anomalies of temperature, salinity and streamfunction are reconstructed using $N_{T}$ temperature modes, $N_{S a}$ active salinity modes and a barotropic streamfunction mode. The projection coefficients $\mu_{k}^{T}(x, y), \mu_{k}^{S a}(x, y), \mu_{0}(x, y)$ are continuous functions that are converted into a discrete set of variables using a truncated two dimensional Fourier decomposition. The system unknowns that form the state vector of the Kalman filter (see section 4.1) are finally the sines and cosines coefficients $a_{m n k}$ and $b_{m n k}$ defined by:

$$
\mu_{k}(x, y)=\sum_{m n} a_{m n k} \sin 2 \pi\left(m x / D_{x}+n y / D_{y}\right)+\sum_{m n} b_{m n k} \cos 2 \pi\left(m x / D_{x}+n y / D_{y}\right),
$$

where $D_{x}$ et $D_{y}$ are the size of the Fourier domain along the longitude and latitude dimensions. The Fourier decomposition has also the advantage of permitting an analytic, and thus exact, computation of horizontal derivatives such as horizontal velocities and relative vorticity.

The Fourier decomposition provides a periodic solution on a square domain, as a consequence, any data situated close to the boundary of the domain influences the field on the opposite boundary. To avoid such effect, the periodic domain must be large enough such that no data is used within an area closer than one covariance scale to the domain boundary. We define the Fourier domain as a square $1280 \mathrm{~km}$ side, centered at $41.5^{\circ} \mathrm{N}-18^{\circ} \mathrm{W}$. Data are selected in a smaller area as shown 
on Figure 1. The horizontal resolution is given by the number of Fourier components taken into account. We use 16 Fourier components in each direction and apply a circular truncation, the shortest half wavelength is then $40 \mathrm{~km}$.

\section{The estimation problem}

\subsection{Formulation of the Kalman filter}

We use a Kalman filter to produce daily estimates of the 3D fields, represented by the vector of Fourier coefficients. This linear estimator, in which observations are introduced sequentially, carries information forward in time. We follow here the formalism introduced par Ide et al. [1997]. At time step $t_{i}$ the observations are analyzed to produce the 3D-fields and corresponding errors. We assume a linear relation between observations $\mathbf{y}_{i}^{\mathbf{o}}$ and the state vector $\mathbf{x}_{i}$, which describes the 3D-fields:

$$
\mathbf{y}_{i}^{\mathbf{o}}=\mathbf{H}_{i} \mathbf{x}_{i}+\epsilon_{i}
$$

Subscript $i$ refers to time $t_{i}, \mathbf{H}_{i}$ is the observation matrix and $\epsilon_{i}$ the observation error. An error covariance matrix $\mathbf{R}_{i}$ is associated with this error, taking into account both measurement errors and error in the representativity of $\mathbf{H}_{i}$. Starting from a forecast $\mathbf{x}_{i}^{f}$ and associated error covariance matrix $\mathbf{P}_{i}^{f}$, the optimal solution $\mathbf{x}_{i}^{a}$ and a posteriori error covariance matrix $\mathbf{P}_{i}^{a}$, are obtained by applying the Kalman gain $K_{i}$ to the innovation vector $\mathbf{d}_{i}$ :

$$
\begin{aligned}
\mathbf{x}_{i}^{a} & =\mathbf{x}_{i}^{f}+\mathbf{K}_{i} \mathbf{d}_{i} \\
\mathbf{P}_{i}^{a} & =\left(I-\mathbf{K}_{i} \mathbf{H}_{i}\right) \mathbf{P}_{i}^{f} \\
\mathbf{d}_{i} & =\mathbf{y}_{i}^{\mathbf{o}}-\mathbf{H}_{i} \mathbf{x}_{i}^{f} \\
\mathbf{K}_{i} & =\mathbf{P}_{i}^{f} \mathbf{H}_{i}^{T}\left(\mathbf{H}_{i} \mathbf{P}_{i}^{f} \mathbf{H}_{i}^{T}+\mathbf{R}_{i}\right)^{-1}
\end{aligned}
$$


The time evolution of the state vector is predicted by a linear equation of the form:

$$
\mathbf{x}_{i}=M\left(\mathbf{x}_{i-1}\right)+\eta_{i-1}
$$

where $\eta_{i-1}$ is the prediction error, with covariance $\mathbf{Q}_{i-1}$. This equation is applied to predict the evolution of the fields (state vector) and corresponding errors, that is used at time $t_{i}$ as forecast and a priori error matrix:

$$
\begin{aligned}
\mathbf{x}_{i}^{f} & =\mathbf{M}_{i-1} \mathbf{x}_{i-1}^{a} \\
\mathbf{P}_{i}^{f} & =\mathbf{M}_{i-1} \mathbf{P}_{i-1}^{a} \mathbf{M}_{i-1}^{T}+\mathbf{Q}_{i-1} .
\end{aligned}
$$

The prediction equation used here is a simple persistence, relaxed to climatology $\left(\mathrm{x}^{c}\right)$ :

$$
\begin{aligned}
\mathbf{x}_{i}^{f} & =\nu \mathbf{x}_{i-1}^{a}+(1-\nu) \mathbf{x}^{c}, \text { with } \nu=\exp -\left(\frac{t_{i}-t_{i-1}}{2 t_{m}}\right)^{2} \\
\mathbf{Q}_{i-1} & =\gamma \mathbf{P}^{c}
\end{aligned}
$$

Such formulation was used for ice cover estimation by Van Woert et al. [2004]. The $\nu$ coefficient represents the autocorrelation between the fields at times $t_{i-1}$ and $t_{i}$. It is approximated by a Gaussian defined by the memory time $t_{m}$. The prediction error is taken as a percentage $(\gamma)$ of the climatological variability $\mathbf{P}^{c}$. Despite the extreme simplicity of the predictive model, and the crude form of the model error matrix, we excluded the computation of a Kalman smoother, because the backwards stepping requires to store the covariance matrices $\mathbf{P}_{i}^{a}$ for all time steps and we did not have the necessary storage space.

\subsection{Kalman filter parameters}

The parameters selected to perform the analysis are summarized in Table 3. The time step for the analysis is 1 day, and the memory time is set to 9 days. The Kalman filter is initialized by an analysis step (equations 13 and 14) where the forecast $\mathbf{x}_{0}^{f}$ is the reference state and the 
corresponding covariance matrix $\mathbf{P}_{0}^{f}$ is taken as the climatological variability covariance $\mathbf{P}^{c}$. This matrix is diagonal and constructed as follows. For a given mode, we first model the horizontal covariances by a Gaussian with a $40 \mathrm{~km}$ e-folding scale (the first Rossby radius is close to $25 \mathrm{~km}$ ). Then this space covariance is Fourier transformed to give the relative variances of the Fourier coefficients that are finally multiplied by the variance of the mode (the eigenvalue of the EOF decomposition). To define the a priori amplitude of the barotropic mode, we rely on previous direct current observations North of the POMME area by Mercier and Colin de Verdière [1985] who found that the barotropic mode has approximately the same variance as the first baroclinic mode, which is identified as the most energetic streamfunction EOF and corresponds to salinity mode 3 (computation of the streamfunction modes with equation 8 changes the relative amplitude of the modes). We thus give the same a-priori normalized amplitude (0.2) to the barotropic mode.

The data presented in section 2 are sorted out according to year day and pseudo-salinities are added where temperature data lack the salinity measurements. To avoid interpreting SOPRANE data as a barotropic current we add an additional constraint of low velocity at depth. A zero velocity, with a RMS value of $5 \mathrm{~cm} \mathrm{~s}^{-1}$ is introduced at $2000 \mathrm{~m}$ for each location of the SOPRANE data. Depending on the day, the length of the data vector varies between 1000 to 12000 .

\section{Validation}

We examine first to which extent the analysis improves the SOPRANE fields. The direct velocity measurements provided by the floats at $300 \mathrm{~m}$ allow the evaluation of the SOPRANE and Kalman systems over the duration of the experiment. The comparison is made with the closest SOPRANE level (325 m). The RMS difference between SOPRANE and float velocities is $8 \mathrm{~cm} \mathrm{~s}^{-1}$ (Table 4). This is above the float and altimetry derived velocity errors. Likely, the time and space resolution of altimetry is not sufficient to fully describe the mesoscale activity and 
the dynamical model without the specification of the exact initial state cannot compensate for the unobserved structures. The same quantity computed from the results of the Kalman analysis that combines the SOPRANE and the float velocities is $3 \mathrm{~cm} \mathrm{~s}^{-1}$ (Table 4).

To illustrate the changes made to the SOPRANE fields by the direct in-situ measurements, we compare the SOPRANE velocities at $100 \mathrm{~m}$ with the analyzed velocities (Figure 7). Here, the observations are mainly VMADCP and float data. Although the general features remain the same, several eddies are shifted and enhanced. For example, the VMADCP observations along $21.5^{\circ} \mathrm{W}$ strengthen and extend the eastward jet near $41.5^{\circ} \mathrm{N}$ and move the eddy seen at $41^{\circ} \mathrm{N}$ eastward.

The consistency of the data sets with the analysis is summarized on Figure 8. For each data type, the RMS residuals are similar to the data error, except for the float current measurements and salinity. Given its limited resolution, the model is not able to resolve the smallest scales described by the floats. For this data set we probably underestimated the representativity error. On the other hand, salinity errors were overestimated. Most salinity data come from the $\theta-\mathrm{S}$ relation, which is better followed than expected in the POMME area.

The comparison of the modal energy distribution in the analysis with that specified a priori provides an overview of the consistency of the solution with a priori statistics. For temperature, the estimated variability fits well that of the data, with $100 \%$ for mode 1 and $80 \%$ for mode 2, falling below $50 \%$ only at mode 4 . The RMS amplitudes for active salinity are similar but reduced by a factor of 2 due to the smaller number of observations and the large error bars on the pseudo-salinity constraints. 


\section{Upper layer annual cycle}

We present here a quantitative study of the upper layer evolution over the annual cycle, analyzing the mixed layer variability and properties, the heat balance and the water mass formation. We limit the analysis to the subarea where error estimates are below $50 \%$ of the a priori error, during the full annual cycle. This defines an $8^{\circ} \times 8^{\circ}$ area centered on $41.5^{\circ} \mathrm{N}-18.0^{\circ} \mathrm{W}$ (Figure 1), and a one year period covering October 13, 2000 to October 12, 2001. All space and time averaging are performed within this area and time window.

\subsection{Annual mean fields}

The streamfunction maps show eddies that slowly evolve and have a residence time in the area larger than the one year period. We define the mean field as the time average of the daily field that we complement by a low-pass $160 \mathrm{~km}$-cutoff filter to remove the signature of these eddies. The resulting mean fields for temperature and current are shown Figure 9 at $200 \mathrm{~m}$ depth.

We compared the mean vertical temperature profile to its equivalent in Reynaud et al. [1998] climatology, which represents mostly the 1970-1980 period in the North Atlantic and noticed that from the surface down to $500 \mathrm{~m}$ depth, the water masses were, on average, warmer by $0.3^{\circ} \mathrm{C}$ during POMME.

The mean velocity profiles indicate weak southward flow at all depths from the surface down to $2000 \mathrm{~m}$, decreasing from $0.5 \mathrm{~cm} \mathrm{~s}^{-1}$ at $100 \mathrm{~m}$ to $0.1 \mathrm{~cm} \mathrm{~s}^{-1}$ at $1500 \mathrm{~m}$ (Figure 10). The mean zonal flow is even weaker, eastward from $0-500 \mathrm{~m}$, and slightly westward between 500 and $1500 \mathrm{~m}$. This scheme agrees with the large scale flow estimated by Paillet and Mercier [1997], who found southward and slightly eastward flow in the 0-800 m layer. According to these authors, the POMME area is located on the path of a southward branch that carries water from the North Atlantic Current to the Azores current. The branches originating from the North 
Atlantic Current can be identified with the two eastward flows entering the western boundary near $45^{\circ} \mathrm{N}$ and $41^{\circ} \mathrm{N}$ (Figure 9). Most of this incoming transport exits the POMME region in the southwest, and some through the northern part of the eastern boundary. There are also several recirculations that involve exchanges between the various branches. The latitudinal variations in the depth range 0-400 $\mathrm{m}$ (Figure 11) show that the mean meridional flow is directed southward at all latitudes, varying between 0 and $-0.9 \mathrm{~cm} / \mathrm{s}$, while the mean zonal flow direction alternates with approximately a $2^{\circ}$ length scale and a maximum amplitude of $1.5 \mathrm{~cm} / \mathrm{s}$.

The surface intensification noticed in the mean current is also evidenced in the turbulent component of the flow (Figure 10). Area averaged EKE is close to $4010^{-4} \mathrm{~m}^{2} \mathrm{~s}^{-2}$ in the top $400 \mathrm{~m}$ and decreases rapidly below. In this upper layer, EKE increases with latitude, from $2010^{-4} \mathrm{~m}^{2} \mathrm{~s}^{-2}$ in the South to $9010^{-4} \mathrm{~m}^{2} \mathrm{~s}^{-2}$ in the North (not shown). The intensification occurs mostly in the western corner, it is related to the North Atlantic Current energy source (see Le Cann et al. [2005] and Assenbaum and Reverdin [2005]). A similar North-South EKE gradient was reported by Bowerman et al. [1997] from repeated ADCP sections although with higher EKE level (150 to $20010^{-4} \mathrm{~m}^{2} \mathrm{~s}^{-2}$, due to unfiltered high frequencies and high data noise). Martins et al. [2002] estimates of EKE level from altimetry range between 50 and $10010^{-4} \mathrm{~m}^{2} \mathrm{~s}^{-2}$.

\subsection{Annual heat budget}

The heat budget over the upper layer of thickness $D$ can be approximated by:

$$
\frac{\partial H}{\partial t}+\int_{-D}^{0} \rho C_{p} \vec{u} . \nabla T d z=Q_{H}
$$

where $\frac{\partial H}{\partial t}$ is the rate of change of heat content, the second term is the horizontal heat advection and $Q_{H}$ the air-sea heat flux. We select $400 \mathrm{~m}$ as the base of the layer, below the maximum mixed layer depth and we neglect the vertical exchanges at the base of the layer that we cannot quantify. 
We evaluated each term of this budget during one year over the POMME area. This approach is purely diagnostic since no heat conservation was imposed in the Kalman filter. The rate of change of heat content is obtained by comparing the area-averaged temperature profiles at the beginning and at the end of the period. We observe an average warming of $0.12^{\circ} \mathrm{C}$ over one year, which corresponds to a heat content rate of change of $+6 \mathrm{~W} \mathrm{~m}^{-2}$. The surface flux term is computed from the heat fluxes produced by Caniaux et al. [2005b] for the POMME experiment. Their data set results from an adjustment of in-situ (ocean and atmosphere) measurements, satellite observations and meteorological products. The averaged heat gain by the ocean for this area and period is $+11 \mathrm{~W} \mathrm{~m}^{-2}$.

We computed the mean and eddy horizontal advection of heat from the temperature and velocity fields. Averaging over one year in the POMME area, we obtain a contribution of the mean term of $+7 \mathrm{~W} \mathrm{~m}^{-2}$, which means that advection by the mean flow cools the POMME area, and an eddy contribution of $-2 \mathrm{~W} \mathrm{~m}^{-2}$. In order to check the stability of those estimates, we computed the same quantities, but changing the size of the area by $25 \%$. The mean term remains unchanged but the eddy terms goes down to $-14 \mathrm{~W} \mathrm{~m}^{-2}$. The zonal average of the mean and eddy contributions (Figure 11) illustrate the scale and amplitude of the eddy term variability that renders this term difficult to estimate with a one year time series. Reverdin et al. [2005] studied the property distribution during the 4 POMME cruises and pointed out a significant contribution of the eddy fluxes, but noticed the strong space variability and the large changes between cruises. We observe the same time and space variability.

Estimates of the heat advection in the North Atlantic performed with a numerical model by Smith et al. [2000] indicate that over 10 years, and at the basin scale, the contribution of the eddy terms to the meridional advection of heat is negligible. Over the POMME area, Giordani 
et al. [2005] evaluated the heat budget terms in their 3D-mixed layer model, they found that the eddy terms were significant, but balanced on annual average by the vertical term. The modeling results seems to hold in the POMME region where a near balance is obtained between air-sea heat fluxes $\left(11 \mathrm{~W} \mathrm{~m}^{-2}\right)$ and the sum of heat content change and heat advection by the mean current $\left(13 \mathrm{~W} \mathrm{~m}^{-2}\right)$.

\subsection{Mixed layer annual cycle}

Several methods for computing the mixed layer depth can be found in the literature (see de Boyer-Montégut et al. [2004] for a review). The most common definitions are based on a threshold value in density or temperature from a near surface value at 10 or $20 \mathrm{~m}$ depth. The temperature based criterion appears to be the most robust away from barrier layer regions. The choice of the temperature threshold $(\Delta T)$ depends on the data set and on the objectives of the study. Small $\Delta T$ follows more closely the mixing layer and the re-stratification events. We tested 3 thresholds: $0.2,0.5$ and $0.7{ }^{\circ} \mathrm{C}$, starting from $z=20 \mathrm{~m}$. The lowest value is recommended by de Boyer-Montégut et al. [2004] while $\Delta T=0.5^{\circ} \mathrm{C}$ is a widely accepted value. We selected this latter criterion because in the POMME region, it gives the best agreement between the mixed layer depths calculated from the analysis and those determined from visual inspection of individual CTD profiles. The time series of the mixed layer depth, averaged over $2^{\circ}$ latitude bands, are shown on Figure 12 for $\Delta T=0.5^{\circ} \mathrm{C}$. Results obtained for $0.2^{\circ} \mathrm{C}$ and $0.7^{\circ} \mathrm{C}$ show similar evolutions, $20 \%$ shallower or $10 \%$ deeper respectively.

Mixed layer deepening starts slowly at the end of summer and intensifies in early January (Figure 12) in response both to storm enhanced mixing and to accumulated negative surface buoyancy fluxes. The maximum mixed layer depth occurs in March (days 425-435) at the time when the surface buoyancy flux goes to zero. It increases from $110 \mathrm{~m}$ at $38.5^{\circ} \mathrm{N}$ to more than 
$250 \mathrm{~m}$ at $44.5^{\circ} \mathrm{N}$. The maximum mixed layer depth is reached earlier in the south of the POMME area in agreement with the temporal shift of the zero-crossing of the surface buoyancy fluxes. During this period, the deepening phases alternate with slight shallowing. A late short deepening event is seen in the North at the end of March (day 455). The deepening of the mixed layer is progressive and the largest deepening speed observed $(5 \mathrm{~m} /$ day) are reached only during short periods. On the opposite, re-stratification, which starts in April for approximately 80 days, occurs during two main events with sustained 4-7 m/day speed that accomplish most of the restratification. It must be noted that re-stratification starts earlier in the numerical simulations of Giordani et al. [2005]. As noticed on the zonal averages, the maximum depth of the mixed layer is not reached simultaneously over the POMME area. The time and space variability is clearly seen on the daily maps (Figure 13). While the mixed layer depth is maximum in the North-East at the beginning of March, a secondary deepening occurs in the North-West at the end of this month. On both maps the horizontal structure of the mixed layer is shaped by the mesoscale.

\subsection{Thermocline ventilation}

The averaged depth and density of the mixed layer over the period of maximum depth (March 6 to 24) are presented in Figure 14. Although the buoyancy forcing is intensified in the Northwest corner (see Caniaux et al. [2005b]), the mixed layer is, on average densest in the Northeast corner. This fact was already noticed by Paillet and Arhan [1996] in their simple thermocline model, and attributed to the eastward advection of heat by Ekman and mean currents.

The volume census by potential density class in the mixed layer (Figure 14) indicates that the dominant water formed during winter has a density in the range $26.8-27.0 \mathrm{~kg} \mathrm{~m}^{-3}$. The maximum in the histogram corresponds to a density slightly above $26.9 \mathrm{~kg} \mathrm{~m}^{-3}$ and a mixed layer depth of $230 \mathrm{~m}$. This water is formed North of $42.5^{\circ} \mathrm{N}$. 
The properties and location of the water formed during the 2000-2001 winter can be compared to previous observations. In particular, Paillet and Arhan [1996] analyzed hydrographic sections across the eastern basin of the North Atlantic to study the water mass formation and subduction processes. By comparing three sections along $42^{\circ} \mathrm{N}$, they noticed that in January 1977 , the mixed layer was already more than $200 \mathrm{~m}$ deep, with density over 27.0. In April 1989, although re-stratification already started, the mixed layer depth was still $200 \mathrm{~m}$, and the density over 26.9, in March, 1990, at the time of maximum development, the mixed layer reached $300 \mathrm{~m}$, for a density of 27.0. During those 3 years the mixed layer was deeper and of higher density than during POMME at that latitude and the mode water in the density range 26.8-27.0 was formed further South. Indeed, in May-June 1988, this mode water was found South of $41^{\circ} \mathrm{N}$ in the Bord-Est 2 section at $12^{\circ} \mathrm{W}$ (Paillet and Arhan [1996]).

We now examine the fate of the 26.8-27.0 mode water formed in the POMME area. The zonally averaged density section at the time of maximum mixed layer depth shows that the 26.8 isopycnal outcrops just North of $42^{\circ} \mathrm{N}$ (Figure 15). We computed the volume flux of the 26.827.0 water across $42^{\circ} \mathrm{N}$, between $22^{\circ} \mathrm{W}$ and $14^{\circ} \mathrm{W}$. This flux varies between 0 and $-510^{6} \mathrm{~m}^{3} \mathrm{~s}^{-1}$ over the year (Figure 16), mainly because of the current changes, the layer thickness varying only by $30 \%$. The annual mean flux equals $-1.410^{6} \mathrm{~m}^{3} \mathrm{~s}^{-1}$. It can be converted to a subduction rate after dividing by the outcrop surface. Admittedly, it will be a rough estimate of the subduction rate, since it assumes that the water that crosses $42^{\circ} \mathrm{N}$ stems from the mixed layer and will not be entrained again, and neglects exchanges through the zonal boundaries.

The zonally averaged outcrop of the 27.0 isopycnal is outside the analysis area. Its position was inferred from SST data as being approximately $45.5^{\circ} \mathrm{N}$. This gives an outcropping area for this density class of ( $8^{\circ}$ longitude by $5^{\circ}$ latitude). We obtain a subduction rate of $120 \mathrm{~m}$ per year. 
Valdivieso et al. [2005] estimated the subduction rate with CLIPPER numerical model for a typical year forced by climatology. In the POMME area they obtained values ranging between 50 and $150 \mathrm{~m}$ per year for this density class.

\section{Conclusion}

The daily 3D fields of temperature, salinity and current produced from the in-situ POMME data set, combined with satellites products were analyzed to study the annual cycle of the upper layer.

During the one year period observed by POMME, the mean circulation in the upper $400 \mathrm{~m}$ resembles the scheme determined by Paillet and Mercier [1997] from hydrography data collected between 1985 and 1992 . The mean currents are characterized by two zonal veins entering the area at 45.5 and $41.5^{\circ} \mathrm{N}$, and southward mean advection. The meridional component of the flow carries cold water southward, thus contributing to cool the POMME area. The annual mean heat budget shows that advection by the mean current nearly balances the warming by the surface heat fluxes. The contribution of the eddy terms was not accurately diagnosed because of its large space and time variability.

The mixed layer depth varies in response to the wind and thermodynamical forcing. The maximum mixed layer depth is reached in March. Zonally averaged over the POMME area, the maximum depth is $100 \mathrm{~m}$ South of $38^{\circ} \mathrm{N}$, it increases rapidly North of $42^{\circ} \mathrm{N}$ to reach $270 \mathrm{~m}$ North of $45^{\circ} \mathrm{N}$. This discontinuity region was located further North during the 2000-2001 winter than in the climatological analysis of Marshall et al. [1993] or in the data from the 1977 and 1988-1990 period analyzed by Paillet and Arhan [1996]. Therefore, the subpolar mode water formed in the North of POMME area has a lower density (26.8-27.0) than the mode water formed in the same area in 1977 and 1988-1990, which were in the density range 27.0-27.1 (Paillet and 
Arhan [1996]). Unlike the climatology, the mixed layer observed during POMME has a marked mesoscale structure. The date at which the maximum depth is reached varies by more than two weeks over the POMME region. The area of maximum density is on average located in the Northeast which does not correspond to the area of maximum air-sea buoyancy fluxes (located in the Northwest), showing the important role of advection in this process.

On zonal average, the mode water in the density class $26.8-27.0$ is continuously advected southward across the $42^{\circ} \mathrm{N}$ latitude. The resulting annual mean transport reaches $1.410^{6} \mathrm{~m}^{3} \mathrm{~s}^{-1}$, which corresponds to an approximate subduction rate of $120 \mathrm{~m} / \mathrm{year}$.

Acknowledgments. The authors thanks all the scientists, engineers, technicians and crew of the research vessels for the time spent at sea for collecting this enormous data set. We also acknowledge the valuable contribution of the SOPRANE team, and particularly Sylvie Giraud, from CLS-ARGOS. Remarks from one of the reviewers greatly helped improving the manuscript. This work was supported by IFREMER, CNRS and the French programm PATOM.

\section{References}

Assenbaum, M., and G. Reverdin (2005), Near Real-Time Analyses of the mesoscale Circulation during the POMME Experiment. Deep Sea Res., in press.

Bowerman, S. J., and H. Leach (1997), Eddies in the northeastern North Atlantic: statistics from observations from a moving ship, J. Geophys. Res., 102(C10), 23,041-23,062.

de Boyer-Montégut, C., G. Madec, A.S. Fischer, A. Lazar and D. Iudicone, (2005), Mixed layer depth over the global ocedan: an examination of profile data and a profile-based climatology,J. Geophys. Res., 109, (C12), C12003, 10.1029/2004 JC002378. 
Caniaux, G., A. Brut, D. Bourras, H. Giordani, A. Paci, L. Prieur and G. Reverdin, (2005), A one year Sea Surface heat, freshwater and momentum budget in the North Eastern Atlantic basin during the POMME experiment. Part I: Flux estimates. submitted to J. Geophys. Res., this issue.

Caniaux, G., S. Belamari, H. Giordani, A. Paci, L. Prieur and G. Reverdin,(2005), A one year Sea Surface heat, freshwater and momentum budget in the North Eastern Atlantic basin during the POMME experiment. Part II: Flux correction. submitted to J. Geophys. Res., this issue.

Cunningham, S.A., Circulation and volume flux of the North Atlantic using synoptic hydrographic data in a Bernouilli inverse (2000), J. Mar. Res., 58, 1-35.

Faucher, P., M. Gavart, and P. De Mey, (2002), Isopycnal empirical orthogonal functions (EOFs) in the North and tropical Atlantic and their use in estimation problems, J. Geophys. Res., 107 (C8), 21,1-21,17.

Fukumori, I. and C., Wunsch, (1991), Efficient representation of the north-Atlantic hydrographic and chemical distributions. Progress in Oceanography, 27, 111-195.

Gaillard, F., J.-C. Gascard and P. Klein (2000). Dynamics of post-convection in the Gulf of Lion. J. Phys. Ocean.30 (12) 3113-3133.

Giordani, H., Caniaux, G. and L. Prieur, (2005), A simplified 3D oceanic model assimilating geostrophic currents: application to the POMME experiment. J. Phys. Ocean.(in press)

Ide, K., P. Courtier, M. Ghil and A. C. Lorenc, (1997), Unified notation for data assimilation: operational, sequential and variational. Journal of the meteorological society of Japan, 75, 1B, 181-189.

Kaplan, A., Y. Kushnir, M.A. Cane, and M.B. Blumenthal, (1997), Reduced space optimal analysis for historical data sets : 136 years of Atlantic sea surface temperatures, J. Geophys. 
Res., 102 (C13), 27835-27860.

Le Cann, B., M. Assenbaum, J-C. Gascard and G. Reverdin,(2005) Observed mean and mesoscale upper ocean circulations in the mid-latitude North-East Atlantic during the POMME experiment. Submitted to J. Geophys. Res., this issue.

Leach, H., S.J. Bowerman, and M.E. McCulloch, (2002), Upper-ocean eddy transports of heat, potential vorticity, and volume in the northeastern North Atlantic - 'Vivaldi 1991', J. Phys. Ocean., 32, 2926-2937.

Marshall, J. C., A. J. G. Nurser, and R. G. Williams (1993), Inferring the subduction rate and period over the North Atlantic, J. Phys. Ocean., 23, 1315-1329.

Martins, S. C. , Hamann, M. and A. F. G. Fiuza, (2002), Surface circulation in the North Atlantic, from drifters and altimetry, J. Geophys. Res., 107, C12, 3217, doi:10.1029/2000JC000345.

Memery, L., G. Reverdin, and J. Paillet, 2004: The POMME Program. Subduction, thermocline ventilation and biogeochemical tracer distribution in the North-East Atlantic Ocean: impact of mesoscale dynamics. Submitted to J. Geophys. Res., this issue.

Mercier, H. and A. Colin de Verdière, (1985), Space and Time scales of mesoscale motions in the eastern North Atlantic. J. Phys. Ocean., 15, 171-183.

Paillet, J. and M. Arhan,(1996), Oceanic ventilation in the Eastern North Atlantic, J. Phys. Ocean., 26, 2036-2052.

Paillet, J. and H. Mercier, (1997), An inverse model of the eastern North Atlantic general circulation and thermocline ventilation, Deep Sea Res., 44, 1293-1328.

Reverdin, G., M. Assenbaum and L. Prieur, The central waters during POMME (09/200009/2001) in the Northeast Atlantic, J. Geophys. Res., this issue. 
Reynaud, T., P. Legrand, H. Mercier and B. Barnier, 1998: A new analysis of hydrographic data in the Atlantic and its application to an inverse modelling study. International WOCE Newsletter, 32, 29-31.

Ricci, S., A. T. Weaver, J. Vialard and P. Rogel, (2005), Incorporating state-dependent Temperature-Salinity constraints in the background error covariance of variational ocean data assimilation. Monthly Weather Review, 133, 317-338.

Smith, R. D., M. E. Maltrud, F. O Bryan and M. W. Hecht, (2000),Numerical simulation of the North Atlantic Ocean at 1/10 . J. Phys. Ocean.30, 1532-1561.

Valdivieso da Costa, M., H. Mercier, and A. M. Tréguier (2005), Effects of the mixed layer time variability on kinematic subduction rate diagnostics. J. Phys. Ocean., in press.

Van Woert, M.L., C.Z.Zou, W.N. Meier, P.D. Hovey, R.H. Preller, and P.G. Posey, 2004: Forecast verification of the Polar Ice Prediction System (PIPS) sea ice concentration fields. Journal of Atmospheric and Oceanic Technology, 21 (6), 944-957. 


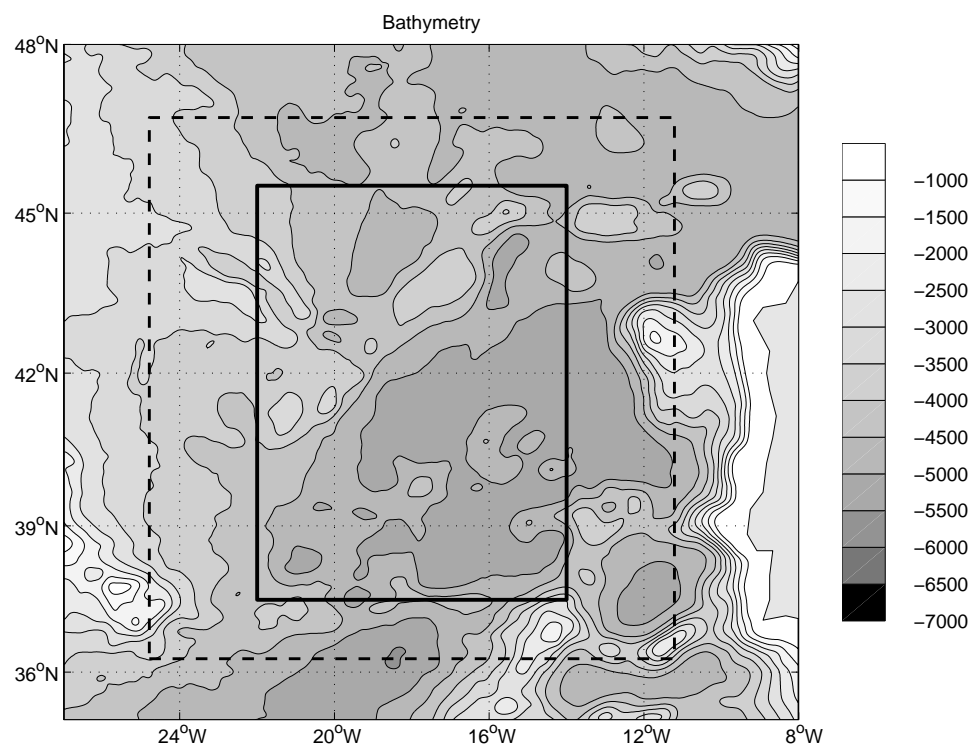

Figure 1. Bathymetry of the POMME area with $1000 \mathrm{~m}$ contour level. The various domains defined for the analysis are indicated. Data inside the dashed line are used for the analysis, results are presented and analyzed inside the region bounded by the plain line. 

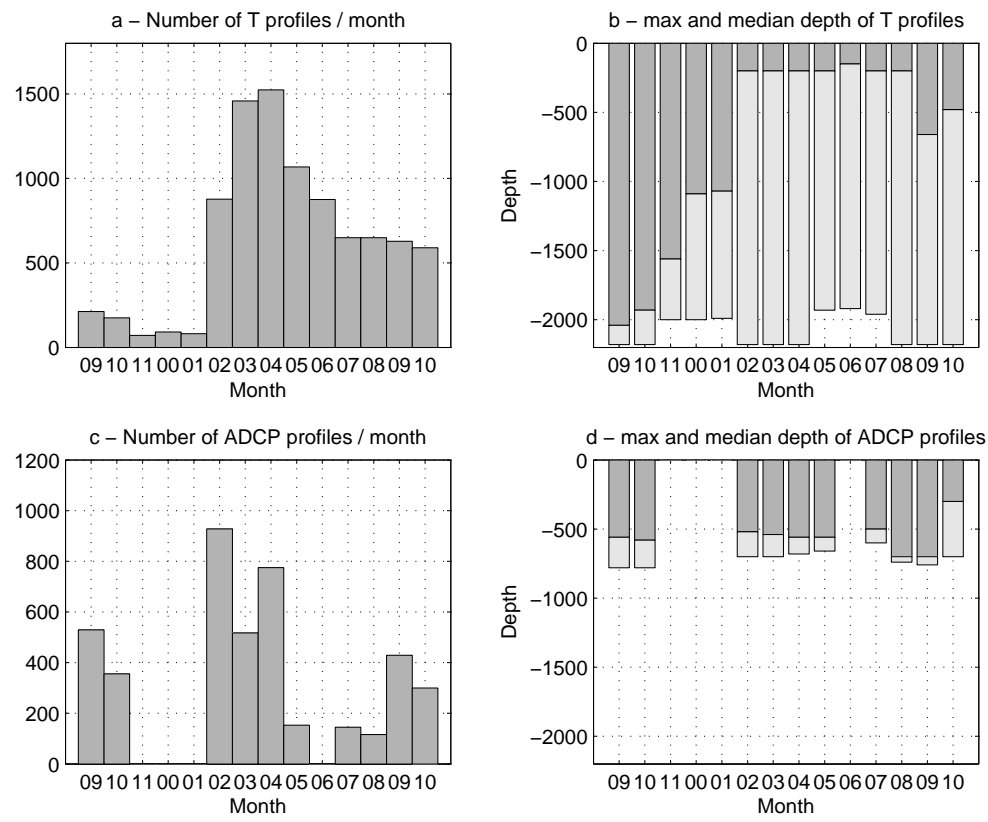

Figure 2. Summary of profile data for temperature and velocity (VMADCP). Number of profiles per month (from September 2000 to October 2001), for temperature (a) and VMADCP (c). Vertical coverage (b and d). Levels covered by at least $50 \%$ of the profiles are in dark gray, maximum depth is in light gray. 

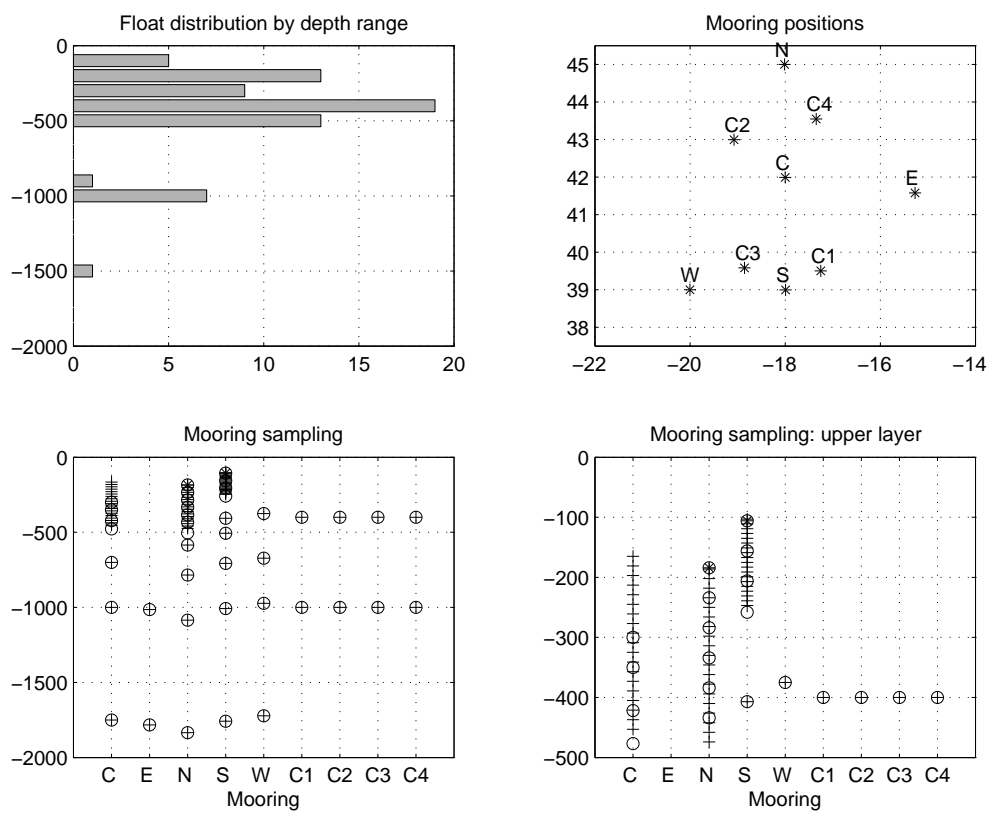

Figure 3. Summary of Lagrangian and Eulerian time series. Float distribution by depth range (top-left). Mooring positions (top-right) and vertical sampling (bottom): temperature sensors (o), salinity sensors (*) and current meters (+). 

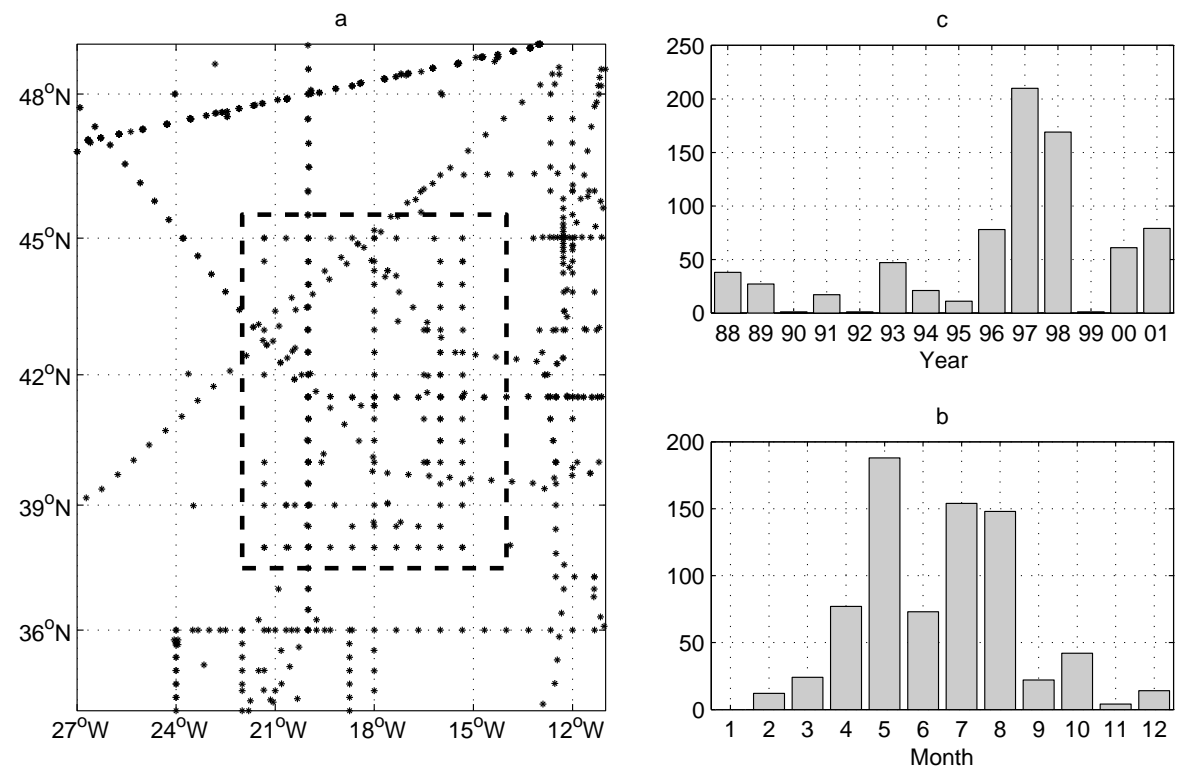

Figure 4. Distribution of CTD profiles used to compute the mean temperature and salinity profiles, the vertical modes and the empirical $\theta-\mathrm{S}$ relation. (a)Positions of the profiles and area of analysis (dashed inner rectangle); (b) distribution in time over the annual cycle; (c) distribution over the 14 years period. 

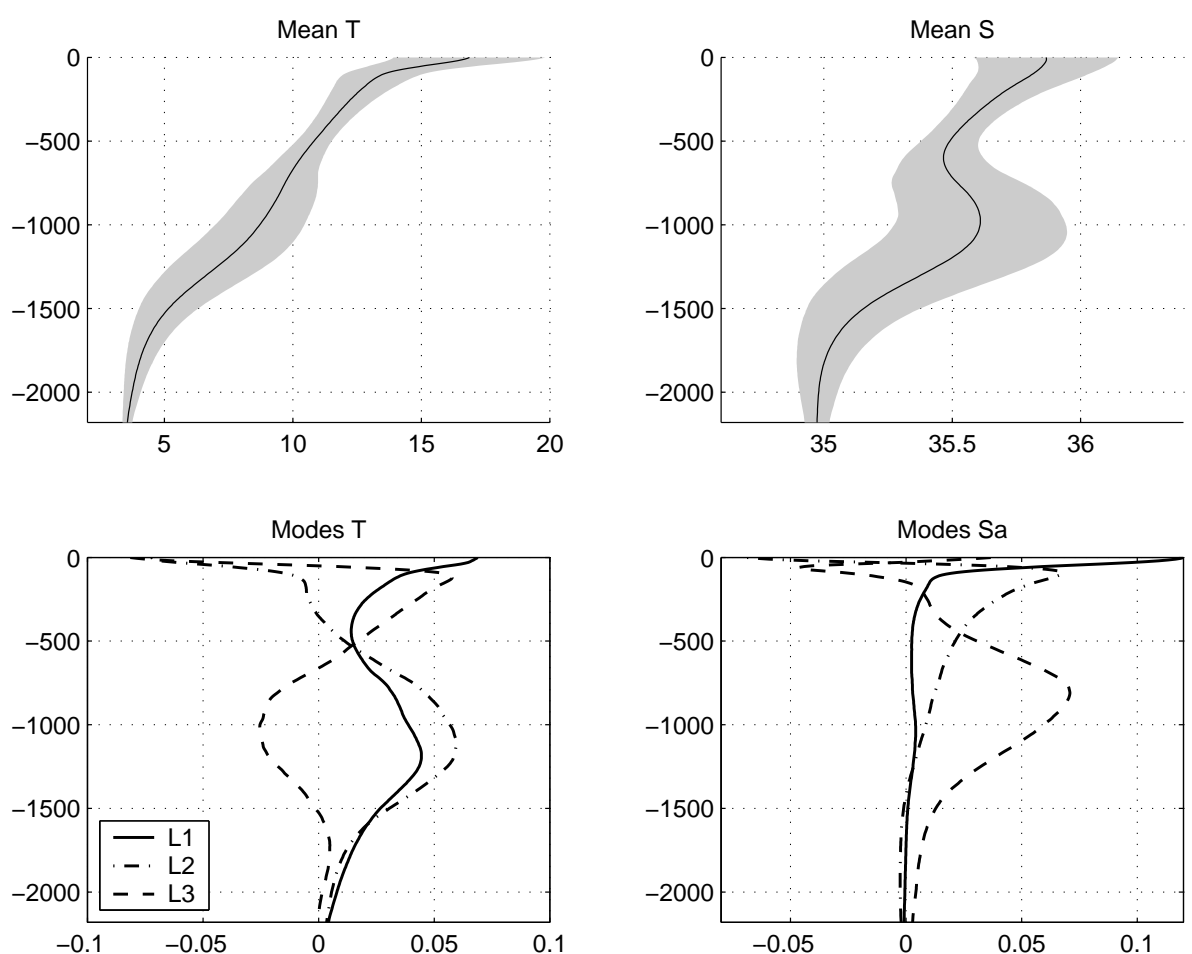

Figure 5. Reference profiles and vertical modes. Top: mean temperature and salinity, and corresponding RMS variability (shaded area). Bottom: The leading vertical modes for temperature (left) and active salinity (right). 

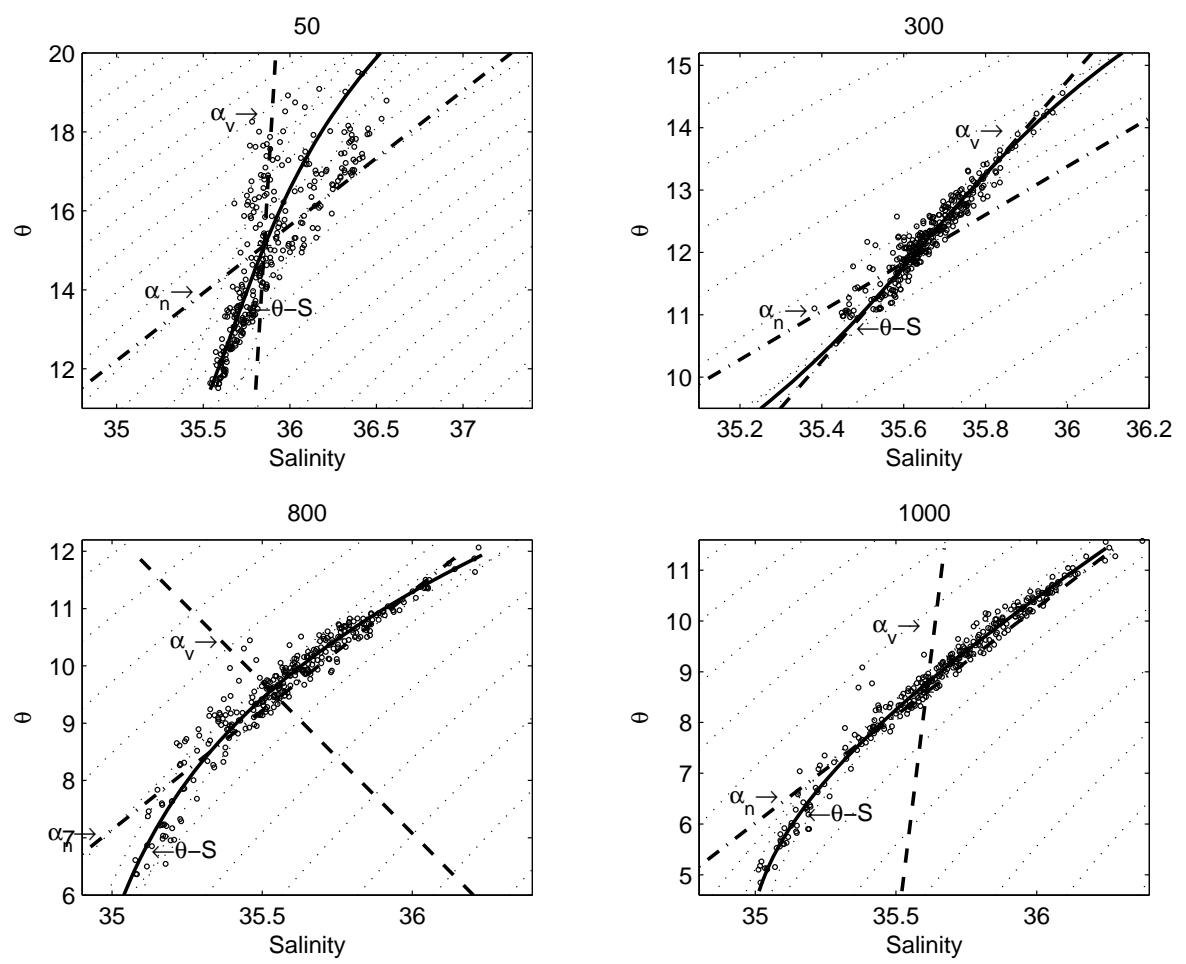

Figure 6. $\theta$-S diagram of the POMME CTD, presented at different levels $(50,300,800$ and $1000 \mathrm{~m})$. The empirical $\theta$-S relation $\left(\alpha_{o b s}\right)$ obtained for this level is overlayed (plain line). Also shown are the neutral linearized relation $\left(\alpha_{n}\right)$ and the relation deduced from the ratio of the vertical derivatives $\left(\alpha_{v}\right)$. 


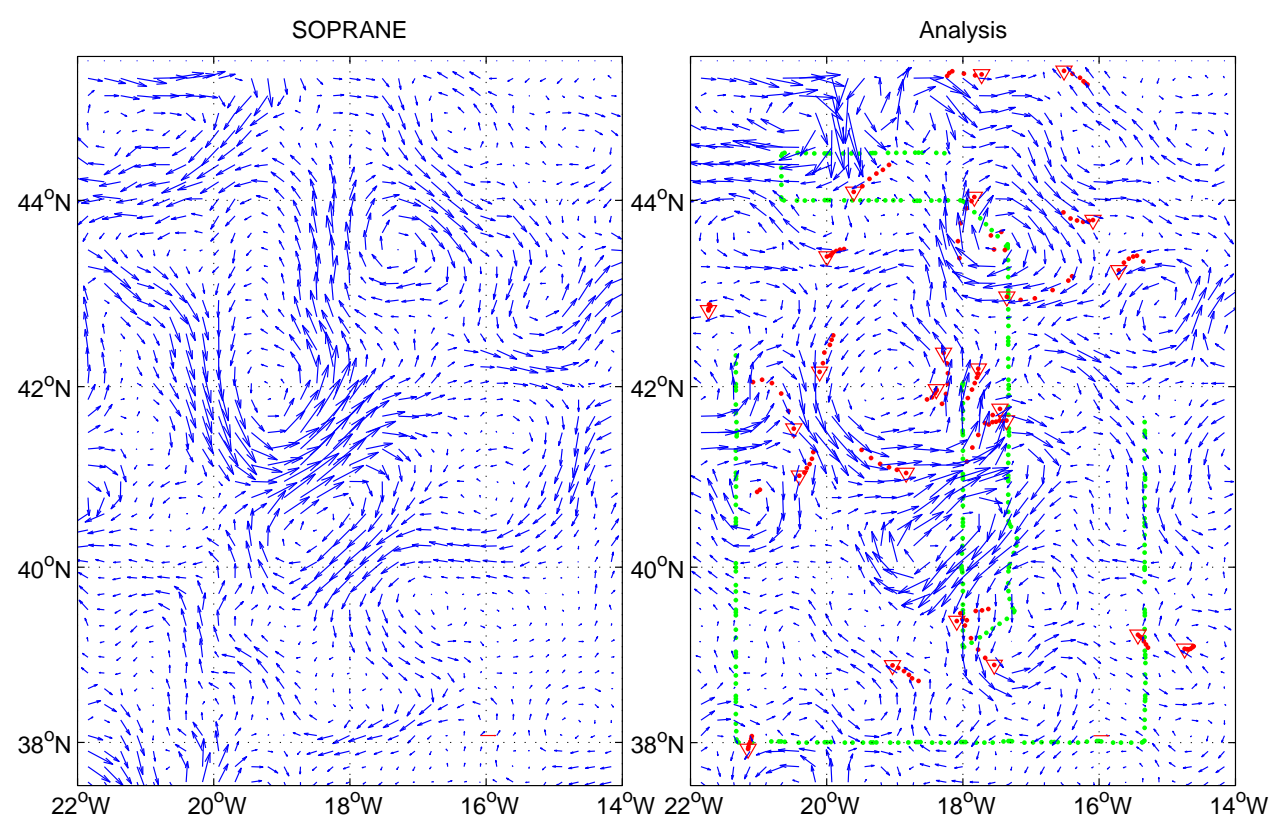

Figure 7. Contribution of in-situ measurements to the velocity field estimation. Velocity field at $100 \mathrm{~m}$ on February, 14, 2001. Left: SOPRANE field(used in the analysis). Right: the same field produced by the analysis after combination with in situ data. The position of the most influent measurements of the last 5 days are indicated: VMADCP (green dots), floats (red triangles). 

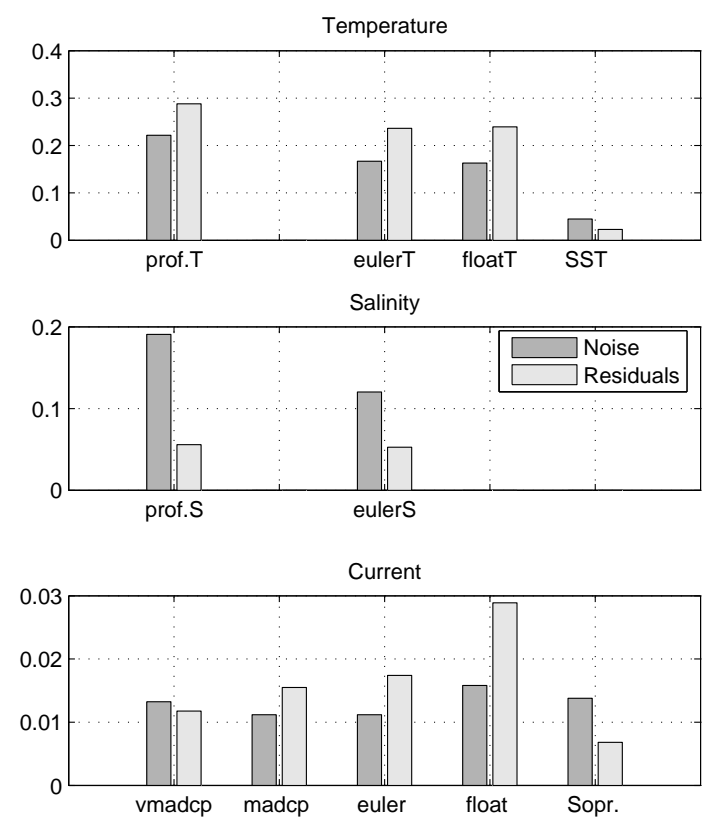

Figure 8. Residuals of the analysis (right bar) compared to the total RMS a priori error (left bar), for the 3 variables (top: temperature, center: salinity, bottom: current). They are presented grouped by data type, from left to right. 1: profiles (T, S or VMADCP), 2: Moored ADCP, 3: Eulerian point measurements (T, S or current), 4: Lagrangian measurements (T or current), 5: 2D fields at one level (SST or Soprane). 

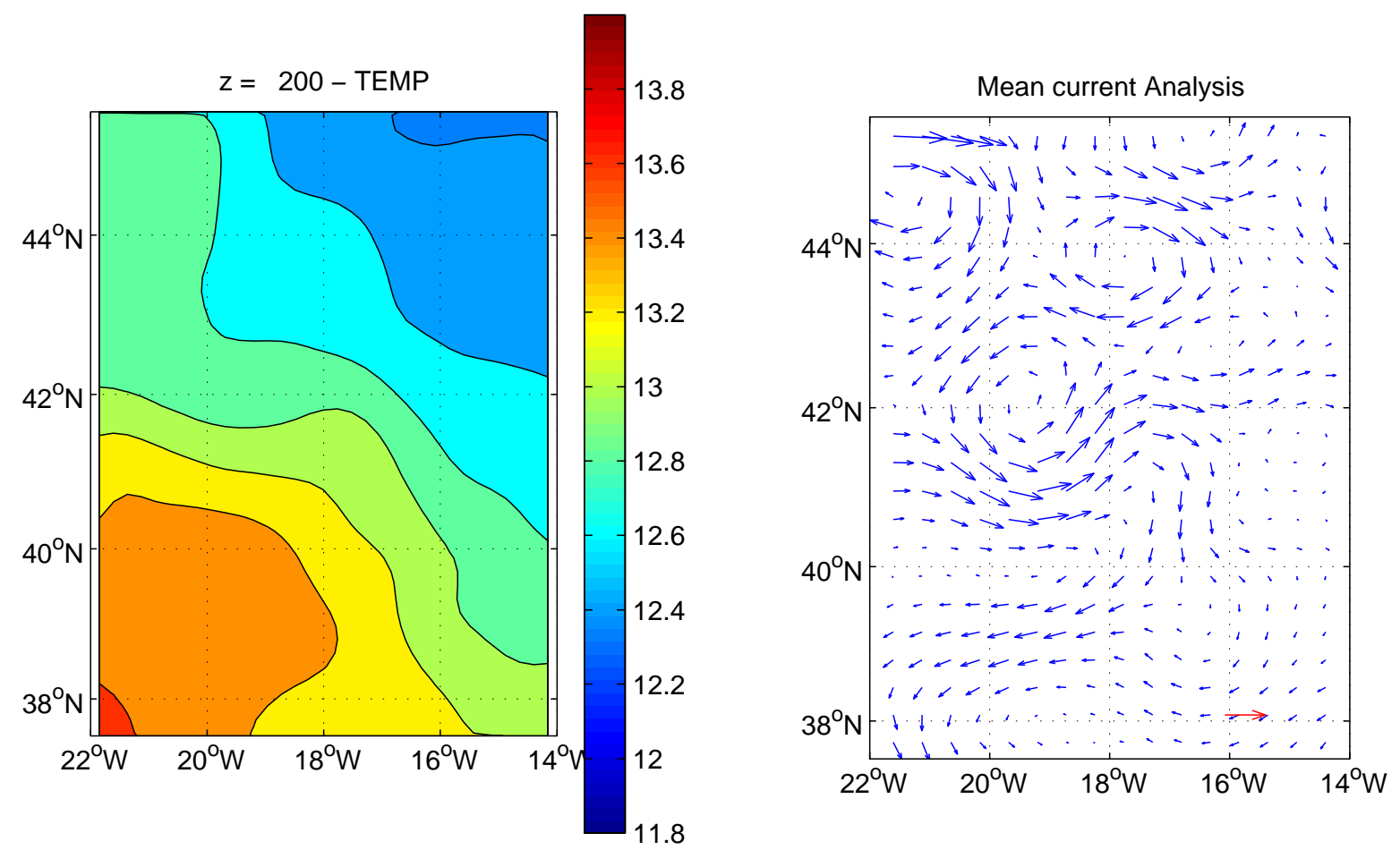

Figure 9. Annual mean fields at $200 \mathrm{~m}$. The time average is low pass filtered with with $160 \mathrm{~km}$ cutoff. Left: temperature, right: current (scale in red is $5 \mathrm{~cm} \mathrm{~s}^{-1}$ ).
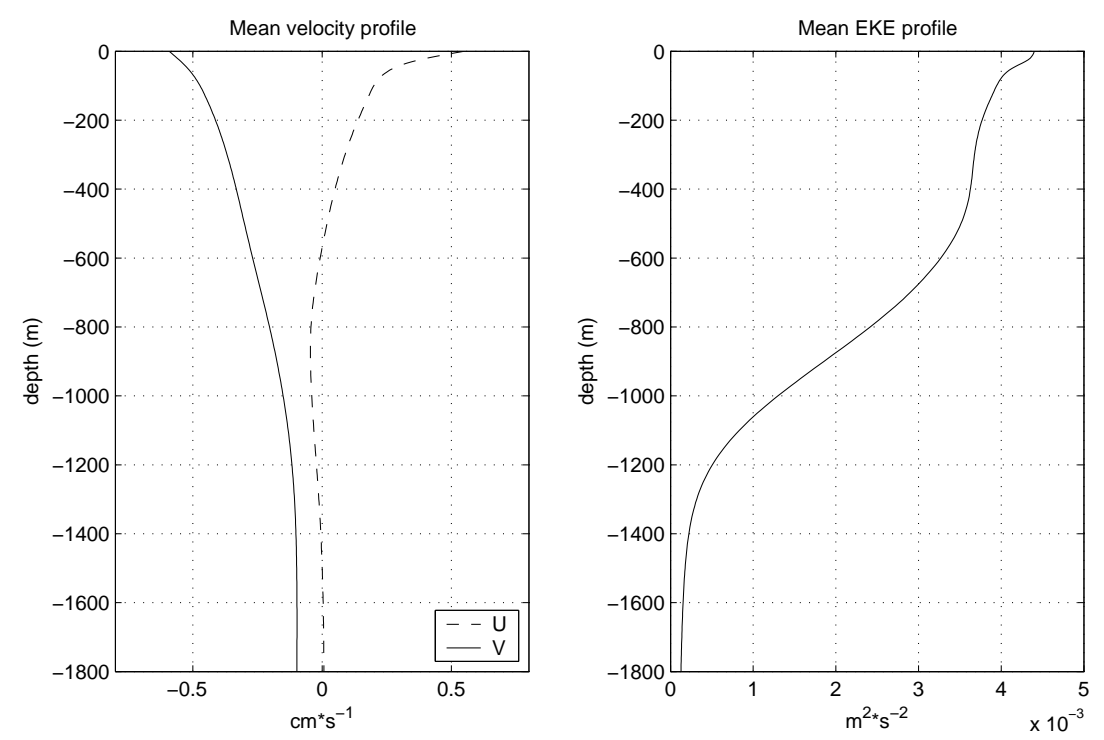

Figure 10. Mean vertical profile of current in $\mathrm{cm} / \mathrm{s}$ (left) and eddy kinetic energy (right) in $\mathrm{m}^{2} \mathrm{~s}^{-1}$ 

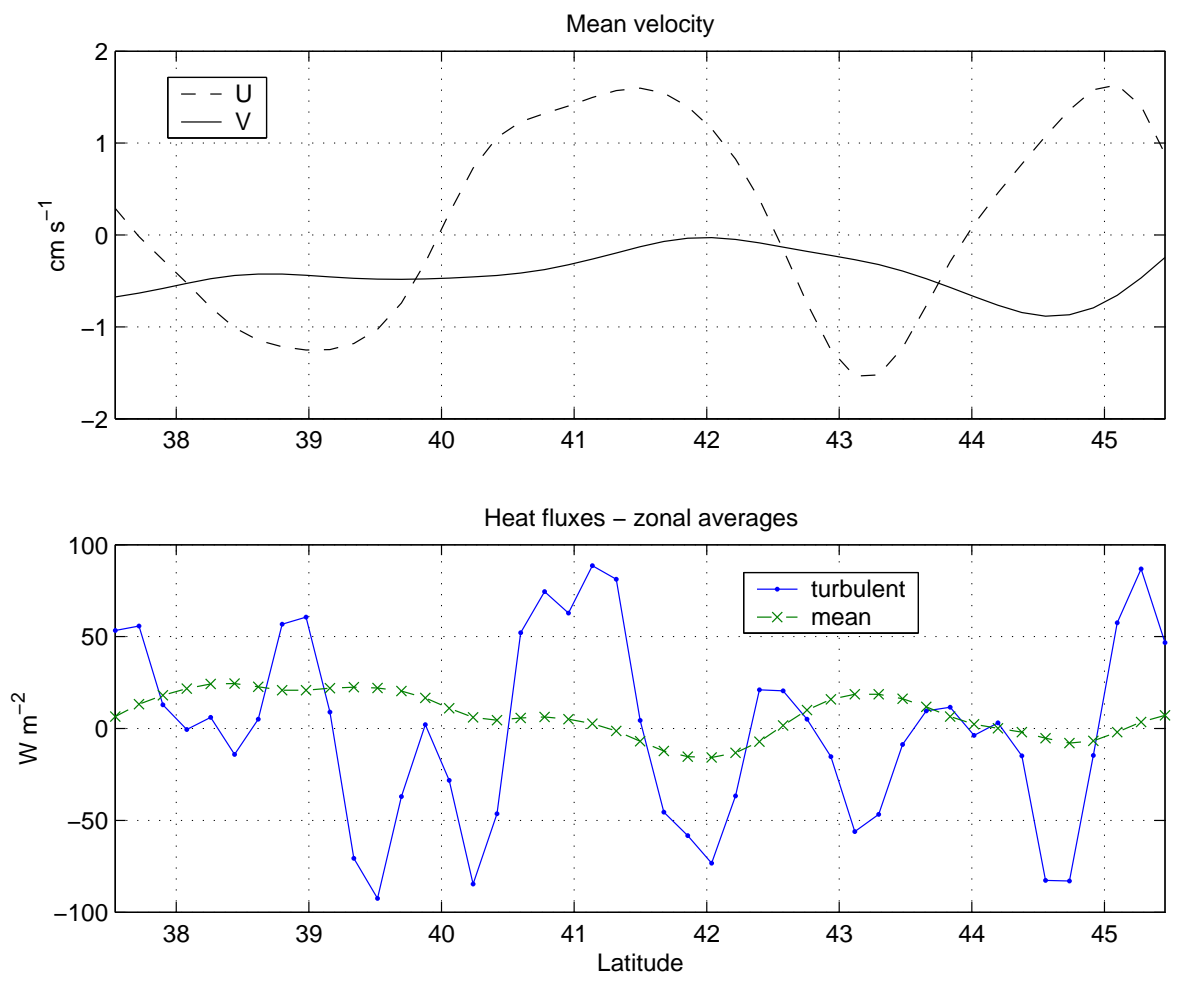

Figure 11. Latitudinal variations of the North and East components of the mean current averaged zonally and over the 0-400 m, layer (top). Mean and eddy components of the horizontal advection of heat, averaged over the same layer and longitude band (bottom). 

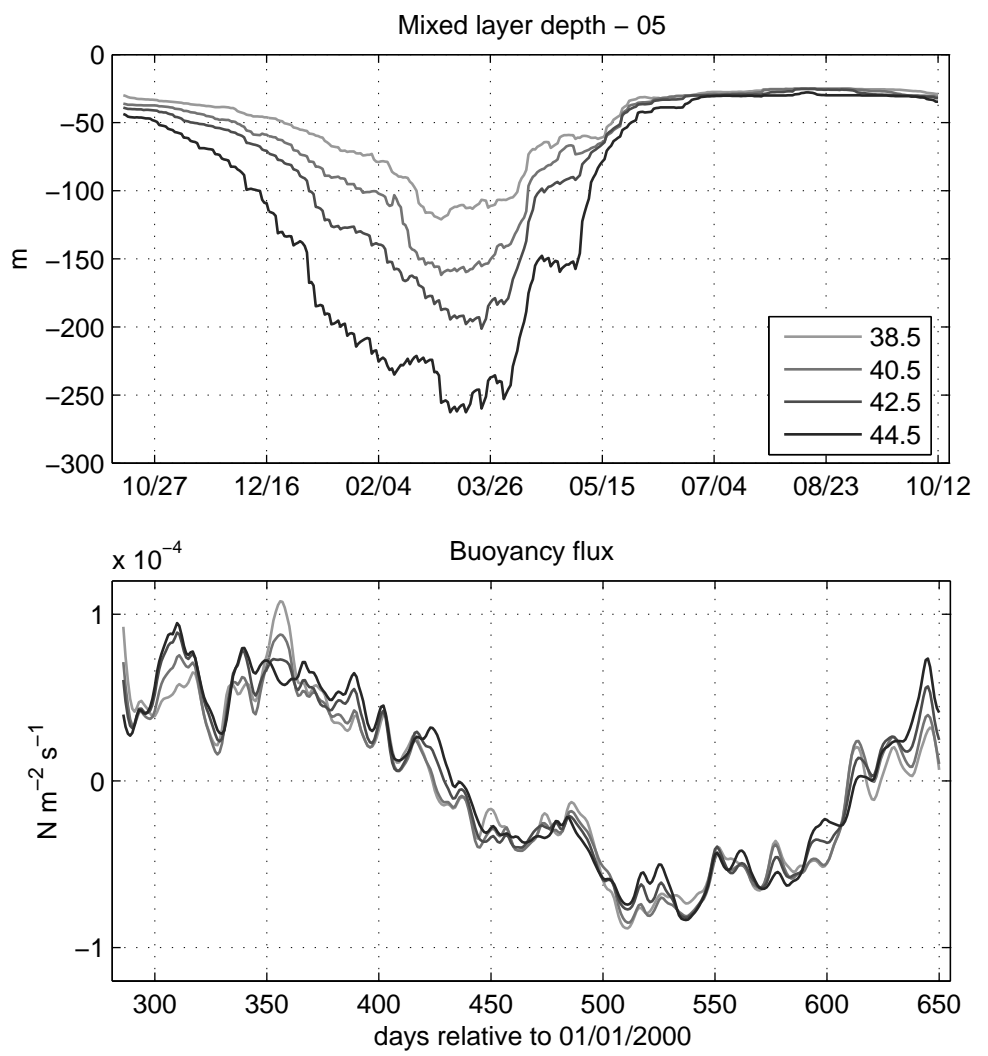

Figure 12. Top panel: Time series of mixed layer depth zonally averaged over $2^{\circ}$ latitude bands. The mixed layer deepens from South $\left(38.5^{\circ} \mathrm{N}\right)$ to North $\left(44.5^{\circ} \mathrm{N}\right)$. Bottom panel: Surface buoyancy fluxes over the same latitude bands computed from Caniaux et al. [2005b] fluxes. 

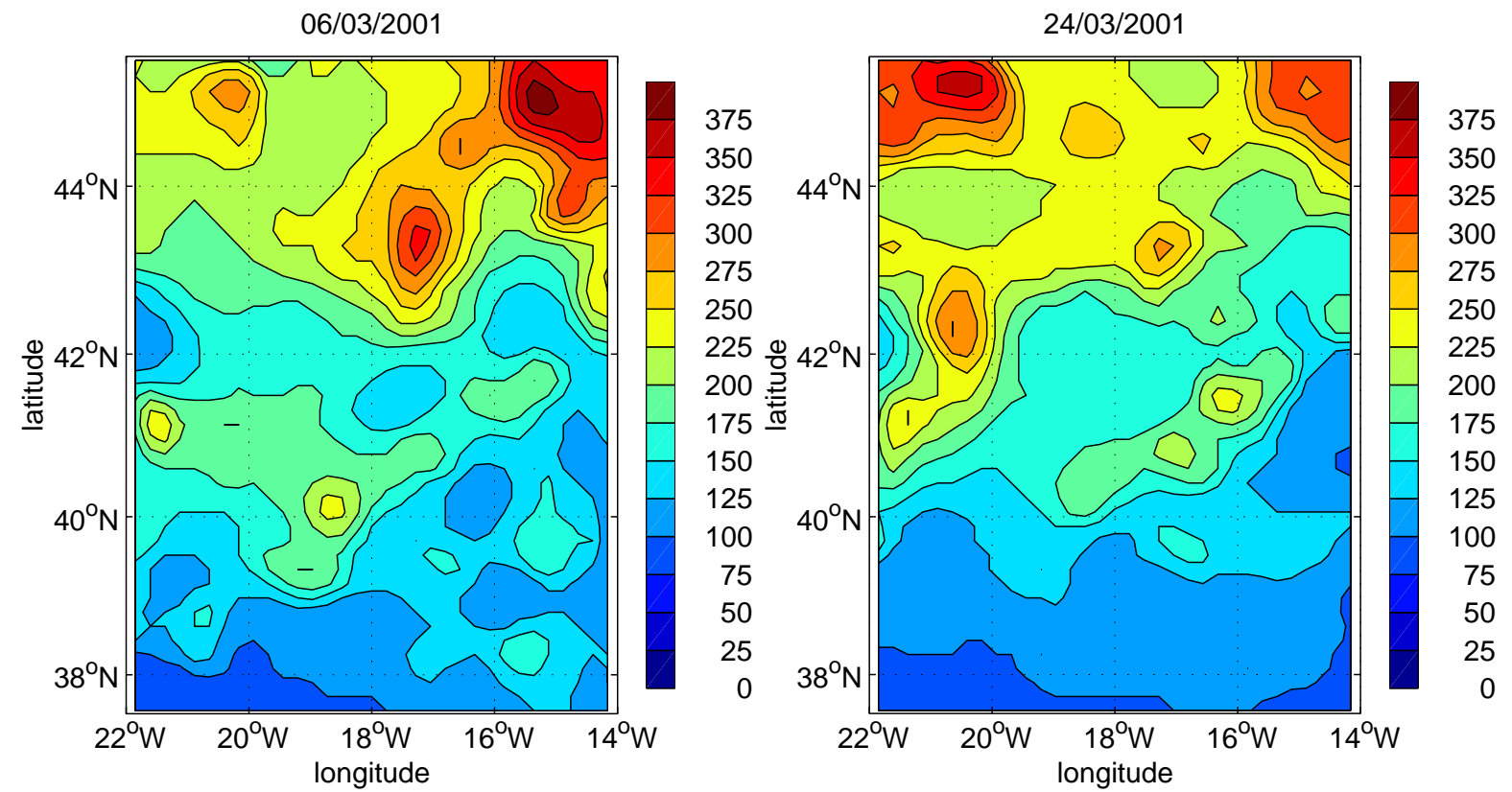

Figure 13. Mixed layer depth during March 2001. Left: On March 6 (day 430) the maximum mixed layer depth is located in the Northeast. Right: on March 24 (day 448), the deepest mixed layer is found in the Northwest. 

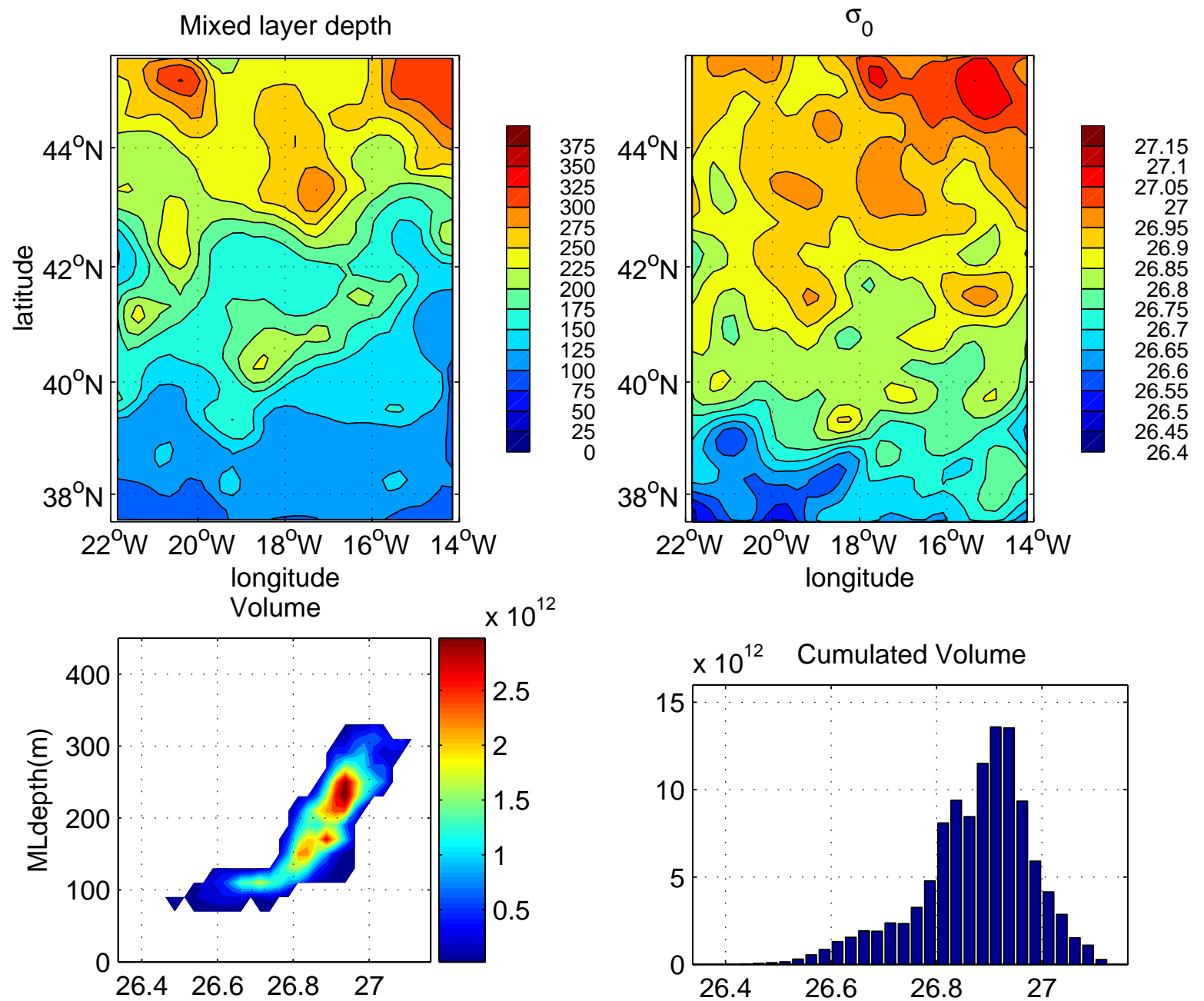

Figure 14. Mixed layer properties during the period of maximum development (averaged between 6 and 24 March 2001). Top left: average mixed layer depth. Top right: average potential density of the mixed layer. Bottom left: Mixed layer volume as a function of mixed layer depth and density classes. Bottom right: Volume of the mixed layer in each density class. 


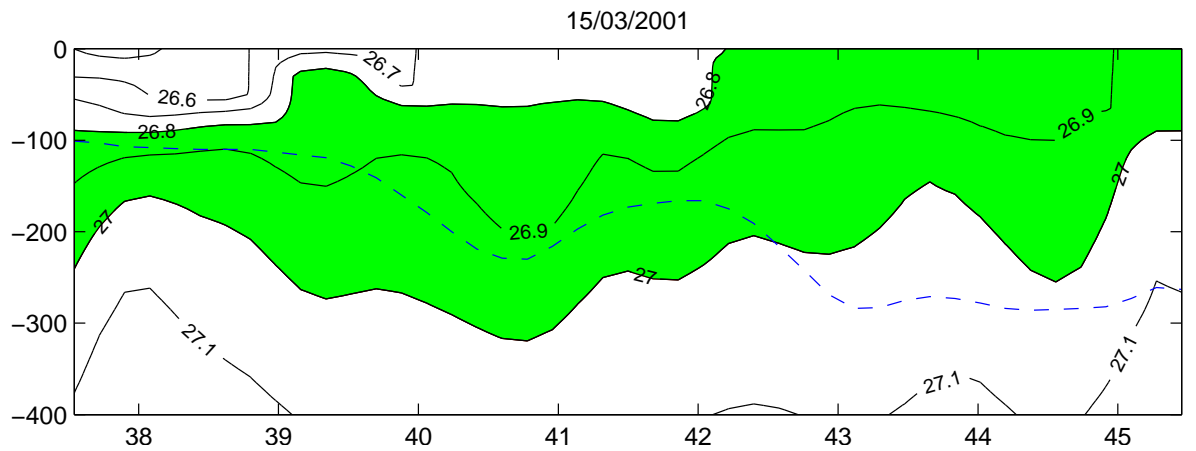

Figure 15. Vertical section of potential density on March 15, 2001 averaged over a $1^{\circ}$ longitude band along $18^{\circ} \mathrm{W}$. The layer in the density class $26.8-27.0$ is shaded. The mixed layer depth is represented by the dashed line. The mixed layer criteria $\left(\Delta \mathrm{T}=0.5^{\circ}\right)$ corresponds to $\Delta \sigma=$ 0.1. The zonal averaging of $\sigma$ smoothes the vertical density gradient more than the mixed layer depth, which explains the slight stratification seen in the mixed layer.
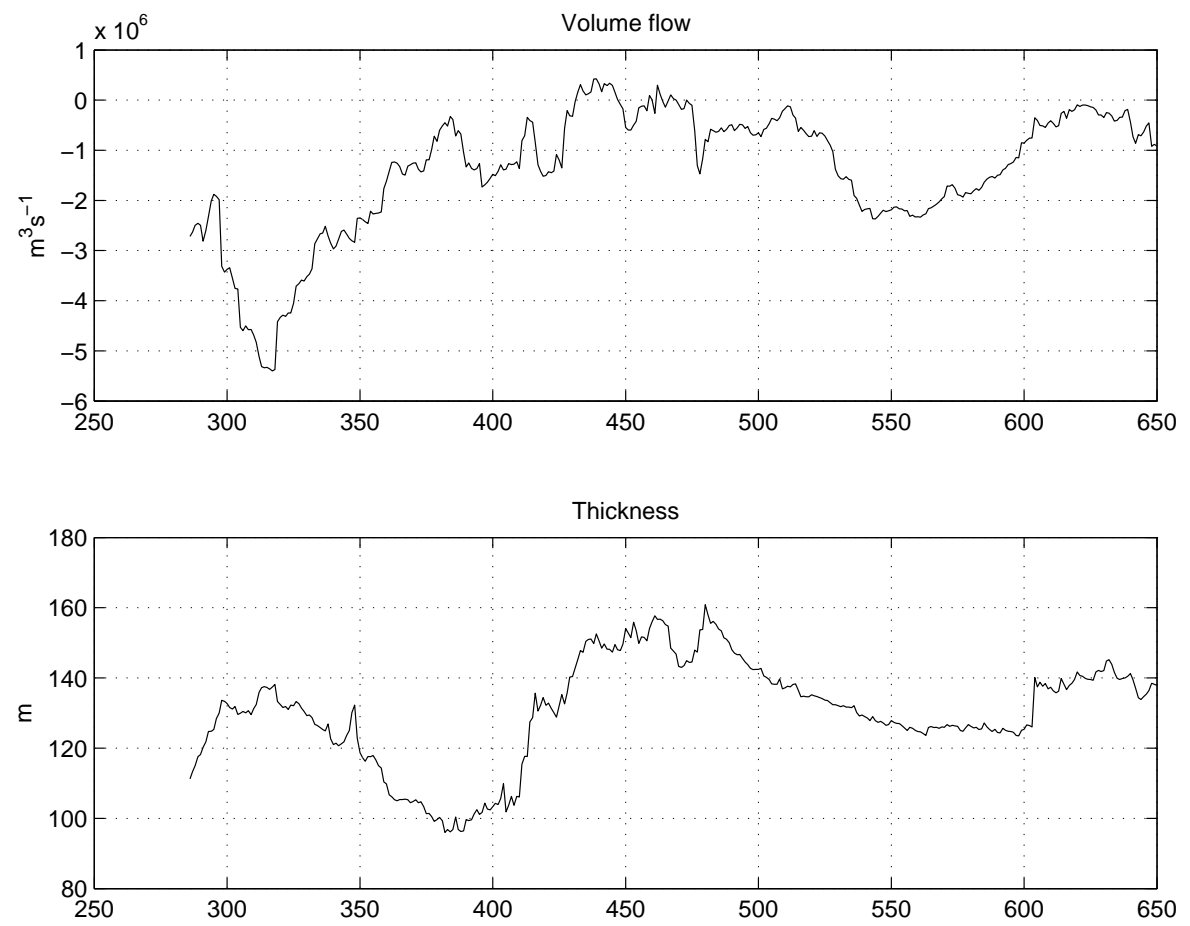

Figure 16. Zonally averaged flux across $42^{\circ} \mathrm{N}$ in the layer defined by the density range 26.8 27.0 (top). The annual mean flux is $-1.410^{6} \mathrm{~m}^{3} \mathrm{~s}^{-1}$. The bottom panel shows the layer thickness. 
Table 1. Types of in-situ data sets used in the analysis and corresponding observed parameters.

\begin{tabular}{lrrrr}
\hline $\begin{array}{l}\text { Cruise data } \\
\text { Cruise }\end{array}$ & $\begin{array}{r}\text { Start } \\
\text { date }\end{array}$ & $\begin{array}{r}\text { End } \\
\text { date }\end{array}$ & $\begin{array}{r}\text { CTD } \\
\text { profiles }\end{array}$ & $\begin{array}{r}\text { VMADCP } \\
\text { profiles }\end{array}$ \\
\hline P0-dtx & $20 / 09 / 2000$ & $27 / 09 / 2000$ & 19 & 251 \\
P0-tha & $18 / 09 / 2000$ & $12 / 10 / 2000$ & 66 & 654 \\
P1-atl-1 & $03 / 02 / 2001$ & $23 / 02 / 2001$ & 79 & 580 \\
P1-atl-2 & $28 / 02 / 2001$ & $19 / 03 / 2001$ & 124 & 333 \\
P1-dtx & $07 / 02 / 2001$ & $02 / 03 / 2001$ & 82 & 681 \\
P2-atl-1 & $24 / 03 / 2001$ & $12 / 04 / 2001$ & 81 & 835 \\
P2-atl-2 & $17 / 04 / 2001$ & $03 / 05 / 2001$ & 62 & 0 \\
P2-dtx & $27 / 03 / 2001$ & $27 / 04 / 2001$ & 75 & 366 \\
VIC1-atl & $22 / 07 / 2001$ & $27 / 07 / 2001$ & 0 & 236 \\
P3-tha-1 & $26 / 08 / 2001$ & $13 / 09 / 2001$ & 83 & 477 \\
P3-tha-2 & $18 / 09 / 2001$ & $08 / 10 / 2001$ & 62 & 493 \\
\hline \hline
\end{tabular}

\begin{tabular}{lrrrr}
\hline $\begin{array}{l}\text { Coriolis profiles } \\
\text { XCTD }^{\mathrm{a}}\end{array}$ & XBT & Profilers & GTS:TE $^{\mathrm{b}}$ & GTS:BA $^{\mathrm{c}}$ \\
\hline 155 & 709 & 947 & 5963 & 446 \\
\hline \hline
\end{tabular}

\begin{tabular}{lrrr}
\hline \hline $\begin{array}{l}\text { Mooring data } \\
\begin{array}{l}\text { Mooring } \\
\text { name }\end{array}\end{array}$ & Latitude & Longitude & $\begin{array}{l}\text { Number } \\
\text { of levels }\end{array}$ \\
\hline C & 42.0 & -18.0 & 27 \\
E & 41.6 & -15.3 & 2 \\
$\mathrm{~N}$ & 45.0 & -18.0 & 31 \\
S & 39.0 & -18.0 & 29 \\
W & 39.0 & -20.0 & 5 \\
C1 & 39.5 & -17.3 & 2 \\
C2 & 43.0 & -19.1 & 2 \\
C3 & 39.6 & -18.9 & 2 \\
C4 & 43.5 & -17.3 & 2 \\
\hline \hline
\end{tabular}

\section{Lagrangian floats}

Type Number Min depth Max depth

\begin{tabular}{lllr}
\hline VCM & 27 & 110 & 864 \\
MARVOR & 29 & 393 & 1526 \\
RAFOS & 12 & 260 & 1035 \\
\hline
\end{tabular}

a XCTDs are mostly POMME data transmitted in real time CORIOLIS

b Data received by the GTS, in TESAC format, they are mostly from POMME Marisonde drifters.

c Data received by the GTS, in BATHY (low resolution) format 
Table 2. RMS errors for different depth ranges, obtained when representing temperature on 8 modes and salinity on 8 neutral modes and 6 active modes. The RMS is computed over all POMME CTD profiles reaching $2200 \mathrm{~m}$.

\begin{tabular}{rrrr}
\hline $\begin{array}{r}\text { Depth range } \\
(\mathrm{m})\end{array}$ & $\begin{array}{r}\text { error on T } \\
(\operatorname{deg} \mathrm{C})\end{array}$ & $\begin{array}{r}\text { error on S } \\
(\mathrm{PSU})\end{array}$ & $\begin{array}{r}\text { error on } \sigma \\
\left(\mathrm{kg} \mathrm{m}^{-3}\right)\end{array}$ \\
\hline $0-800$ & 0.08 & 0.01 & 0.01 \\
$800-1300$ & 0.18 & 0.04 & 0.01 \\
$1300-2200$ & 0.12 & 0.03 & 0.01 \\
\hline
\end{tabular}

Table 3. Configuration selected for the analysis, summary of parameters value. The a priori mode amplitudes have to be multiplied by the scaling factor.

\begin{tabular}{lr}
\hline Size of inversion area $\left(D_{x}=D_{y}\right)$ & $1280 \mathrm{~km}$ \\
Resolution $\left(\lambda_{\min } / 2\right)$ & $40 \mathrm{~km}$ \\
Depth analyzed & $0-2200 \mathrm{~m}$ \\
Period analyzed & Du 13/09/2000 to $12 / 10 / 2001$ \\
Time step of analysis & 1 day \\
Kalman memory time $\left(\mathrm{t}_{m}\right)$ & 9 days \\
Kalman prediction error variance $(\gamma)$ & $1.5 \%$ of climatological variability $/$ day \\
Number of vertical modes & $\mathrm{T}: 8, \mathrm{~S}: 8+6, \Psi: 1 \mathrm{bt}, 6 \mathrm{bcl}$ \\
Apriori amplitudes scaling: & 30 \\
Temperature $\left({ }^{\circ} \mathrm{C}\right)$ & $1,0.72,0.63,0.43,0.35,0.28,0.25,0.22$ \\
Active salinity $(\mathrm{PSU})$ & $0.43,0.28,0.20,0.18,0.13,0.10$ \\
Barotropic $\left(\mathrm{m}^{2} \mathrm{~s}^{-1}\right)$ & 0.2 \\
Horizontal covariance scale & $40 \mathrm{~km}$ \\
\hline
\end{tabular}

Table 4. RMS discrepancy between the direct float velocity measurements in the layer $325 \mathrm{~m} \mathrm{+/-}$ $100 \mathrm{~m}$ and the SOPRANE field (at $325 \mathrm{~m}$ ) or the Kalman analysis (at $320 \mathrm{~m}$ ).

\begin{tabular}{lrr}
\hline Field & $\begin{array}{r}\text { RMS error on U } \\
\left(\mathrm{cm} \mathrm{s}^{-1}\right)\end{array}$ & $\begin{array}{r}\text { RMS error on V } \\
\left(\mathrm{cm} \mathrm{s}^{-} 1\right)\end{array}$ \\
\hline SOPRANE & 8.2 & 8.1 \\
Kalman & 3.0 & 3.3 \\
\hline
\end{tabular}

